\title{
Comparative transcriptomic and metabolic analysis of wild and domesticated wheat genotypes reveals differences in chemical and physical defense responses against aphids
}

\author{
Zhaniya S. Batyrshina', Beery Yaakov ${ }^{1}$, Reut Shavit ${ }^{1}$, Anuradha Singh ${ }^{1}$ and Vered Tzin ${ }^{1,2^{*}}$ (D)
}

\begin{abstract}
Background: Young wheat plants are continuously exposed to herbivorous insect attack. To reduce insect damage and maintain their growth, plants evolved different defense mechanisms, including the biosynthesis of deterrent compounds named benzoxazinoids, and/or trichome formation that provides physical barriers. It is unclear whether both of these mechanisms are equally critical in providing an efficient defense for wheat seedlings against aphids - an economically costly pest in cereal production.

Results: In this study, we compared the transcriptome, metabolome, benzoxazinoids, and trichome density of three selected wheat genotypes, with a focus on differences related to defense mechanisms. We chose diverse wheat genotypes: two tetraploid wheat genotypes, domesticated durum 'Svevo' and wild emmer 'Zavitan,' and one hexaploid bread wheat, 'Chinese Spring.' The full transcriptomic analysis revealed a major difference between the three genotypes, while the clustering of significantly different genes suggested a higher similarity between the two domesticated wheats than between either and the wild wheat. A pathway enrichment analysis indicated that the genes associated with primary metabolism, as well as the pathways associated with defense such as phytohormones and specialized metabolites, were different between the three genotypes. Measurement of benzoxazinoid levels at the three time points $(11,15$, and 18 days after germination) revealed high levels in the two domesticated genotypes, while in wild emmer wheat, they were below detection level. In contrast to the benzoxazinoid levels, the trichome density was dramatically higher in the wild emmer than in the domesticated wheat. Lastly, we tested the bird cherry-oat aphid's (Rhopalosiphum padi) performance and found that Chinese Spring is more resistant than the tetraploid genotypes.

Conclusions: Our results show that benzoxazinoids play a more significant defensive role than trichomes. Differences between the abundance of defense mechanisms in the wild and domesticated plants were observed in which wild emmer possesses high physical defenses while the domesticated wheat genotypes have high chemical defenses. These findings provide new insights into the defense adaptations of wheat plants against aphids.
\end{abstract}

Keywords: Aphid infestation, Benzoxazinoids, Defense, Domestication, Rhopalosiphum padi, Trichome, Triticum aestivum, Triticum turgidum, Wheat

\footnotetext{
* Correspondence: vtzin@bgu.ac.il

${ }^{1}$ French Associates Institute for Agriculture and Biotechnology of Drylands, Jacob Blaustein Institutes for Desert Research, Ben-Gurion University of the Negev, Sede Boqer Campus, 8499000 Midreseht Ben Gurion, Beer-Sheva, Israel

${ }^{2}$ Ilse Katz Institute for Nanoscale Science and Technology, Ben-Gurion University of the Negev, Beer-Sheva, Israel
}

(c) The Author(s). 2020 Open Access This article is distributed under the terms of the Creative Commons Attribution 4.0 International License (http://creativecommons.org/licenses/by/4.0/), which permits unrestricted use, distribution, and reproduction in any medium, provided you give appropriate credit to the original author(s) and the source, provide a link to the Creative Commons license, and indicate if changes were made. The Creative Commons Public Domain Dedication waiver (http://creativecommons.org/publicdomain/zero/1.0/) applies to the data made available in this article, unless otherwise stated. 


\section{Background}

Crop plants are continually exposed to different environmental stress conditions, such as herbivore infestation [1]. Insect herbivory is a crucial factor in yield loss and quality degradation in agricultural crop production. Average losses can reach $20-30 \%$ of yield, and in some cases, they can cause a total yield loss [2]. One of the most economically significant herbivores is found in the aphid family (Hemiptera: Aphididae) [3], a piercingsucking pest that feeds on the phloem sap. Aphid infestation causes direct damage by consumption of water and nutrients, as well as indirect damage by plant virus transmission [4-6]. In response to insect infestation, plants produce constitutive and inducible defenses to reduce damage and enhance their own fitness [7]. Although many plant defenses are produced constitutively during a specific developmental stage, regardless of insect attack, others are inducible in response to insect damage. Examples of herbivore-induced defense mechanisms are the accumulation of toxic chemicals such as benzoxazinoids, glucosinolates, and alkaloids, which are classes of specialized metabolites that function as deterrents. Another mechanism is mechanical defense, including physical barriers such as the increased density of thorns, spikes, or trichomes [8-13]. Most of the toxic defenses are abundant in young seedlings and decrease during development toward the juvenile stage [14-16]. The herbivore-induced mechanisms are mediated by the modification of signaling (i.e., jasmonic and salicylic acid) [17], which allows the plants to conserve metabolic resources and energy to be directed toward growth and reproduction in the absence of insect herbivory.

Wheat is a staple crop that provides $20 \%$ of the world population's caloric and protein intake [18]. It was first domesticated more than 10,000 years ago, making it one of the earliest domesticated crops [19]. The process of domestication, centuries of cultivation, and modern wheat breeding have led to the reduction or narrowing of genetic variation compared to their wild ancestors [20]. This reduction is due to the small initial crop population, coupled with intense selection for agronomic traits, considered as a "domestication bottleneck" [21, 22]. Adaptation of domesticated wheat and wheat varieties to local conditions intensified the reduction, giving rise to landrace cultivars [23]. Moreover, the cultivation of a germplasm with a narrow genetic base entails a risk due to genetic vulnerability to biotic and abiotic stresses, possibly resulting in severe crop losses. By using wild relatives of wheat as a proxy, the genetic diversity of agriculturally important traits can be contrasted before and after domestication [21]. It has been suggested that several agriculturally important traits, such as biotic and abiotic stress resistance, significantly decreased during wheat domestication [24, 25]. This lowered resistance, reported for responses to herbivore attack [26, 27], bacterial blight [28], and fungal disease [29], was revealed in domesticated members of the plant families Fabaceae and Brassicaceae [25]. In contrast, increased resistance of domesticated wheat to aphids was also reported [30]. It was suggested that the tuning of plant domestication defense mechanisms is dependent on pest feeding habits [31].

Integration between transcriptomic and metabolic datasets is commonly used to expose how insects may modify their host plant to their advantage [32, 33]. In this research, we investigated the differences in the transcriptome and metabolome of wheat seedlings, and we studied the effect on the chemical and physical defenses against Rhopalosiphum padi aphids. The variation between Triticum species for cereal aphid resistance has demonstrated the potential of using tetraploid wheat to reveal plant defense mechanisms [34-36]. Therefore, we focused our research on three representative wheat genotypes: i) Svevo, a tetraploid durum wheat cultivar (Triticum turgidum ssp. durum), ii) a wild emmer, Zavitan, a tetraploid ancestor of modern domesticated tetraploids (Triticum turgidum ssp. dicoccoides); both tetraploids have been intensively investigated as potential sources for resistance genes and markers [30, 37]; and iii) the spring wheat genotype Chinese Spring, which is widely used as a reference genome and for cytogenetic studies [20, 38-43]. We investigated young wheat seedlings (11-18 days old), which produce high levels of chemical and physical defenses. The chemical deterrent metabolites (benzoxazinoids) and the physical defenses (trichomes) were analyzed and compared with $R$. padi aphid reproduction. Altogether, this study evaluates the dynamics of defense mechanisms in response to aphid attack.

\section{Results \\ Overview of the transcriptomic dataset differences between the three wheat genotypes}

To investigate the global transcriptomic profile of the three wheat genotypes, leaves from 11-day-old seedlings were collected from genotypes with the same phenology (two-leaf stage; Additional file 2: Figure S1). A comparison of transcriptomic data was performed with annotated gene models found in the Chinese Spring reference genome sequence $[20,38]$, and the mapped sequence reads showed high similarity between the genotypes: Svevo, 95.85\%; Zavitan, 94.68\%; and Chinese Spring, 96.72\% from the total mapped reads (Additional file 1: Table S1). Due to differences in the number of subgenomes, we eliminated all the transcripts that were annotated to the D subgenome or an unidentified subgenome (U). This analysis revealed 42,474 transcripts (Additional file 1: Table S2). The total transcript levels were used to 
conduct a principal component analysis (PCA) plot. As presented in Fig. 1, the PCA plot indicated that samples from each genotype were clustered with one another, while the genotypes were totally separated from each other, with component 1 (45\%) showing a separation of Chinese Spring from the tetraploid wheat genotypes, and component $2(36 \%)$ separating the wild (Zavitan) and cultivated (Svevo and Chinese Spring) wheat genotypes. Overall, the transcriptomic analysis of the three genotypes showed a unique pattern for each one.

\section{Clustering of expression patterns and pathway} enrichment and gene ontology in the transcriptomic data In order to detect differentially expressed genes in the RNA-seq data, the number of sequences associated with each gene (counts) for each sample was used to statistically compare between- and within-condition variability, by a negative binomial generalized linear model, using the $\mathrm{R}$ package DESeq2. The DESeq2 output, compared using the likelihood ratio test (LRT), was subjected to an rlog transformation, and the resulting heatmap clearly divided the overall transcriptional profiles of the two cultivated genotypes (Svevo and Chinese Spring) from the wild genotype (Zavitan), presented in Additional file

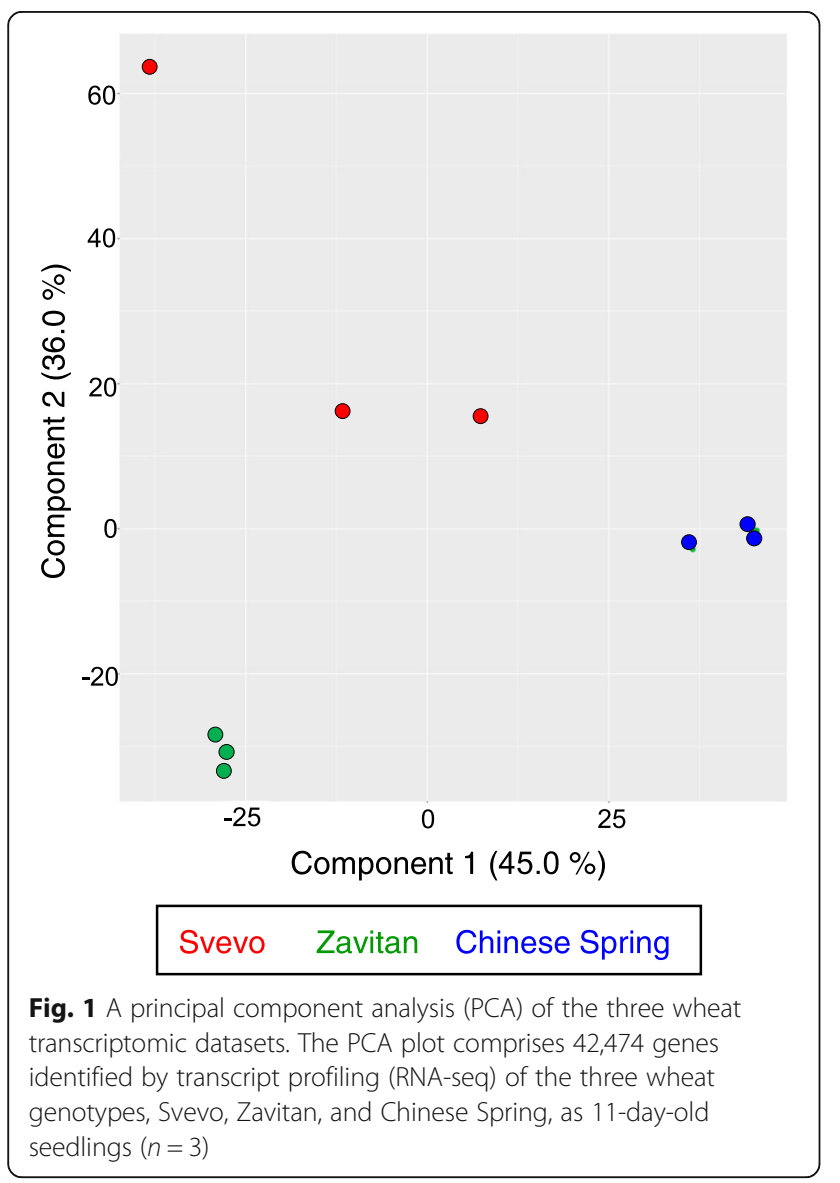

2: Figure S2. The analysis of differentially expressed genes $\left(q\right.$-value $<0.05 ; \mid \log _{2}$ (fold change) $\left.\mid>=1\right)$ resulted in 8735 unique transcripts. We estimated the cluster number of the results using clusGap [44], which suggested dividing the data into eight clusters. The $k$-means analysis was performed on scaled and centered rlog values, and each cluster is represented by the Z-score (standard score) of gene expression from the set of genes showing similar response patterns in the three wheat genotypes (Fig. 2). The eight clusters were divided into five expression groups, derived from trends observed in the standard scores: i) Clusters 1 and 2: genes with a higher level in Zavitan than in Svevo and Chinese Spring. Cluster 2 presents genes with a higher Z-score than Cluster 1. ii) Clusters 3 and 4: genes with a lower level in Zavitan than in Svevo and Chinese Spring. Cluster 4 presents genes with a lower Z-score than Cluster 3. iii) Clusters 5 and 6: genes with moderately lower levels in Svevo than in Zavitan and Chinese Spring. Cluster 5 presents genes with a higher Z-score than Cluster 6. iv) Cluster 7: genes that have lower levels in Zavitan than in Svevo and Chinese Spring. v) Cluster 8: genes that have lower levels in Chinese Spring than in Svevo and Zavitan (Fig. 2). The distribution of genes into the eight clusters is presented in Additional file 1: Table S3.

To elucidate the metabolic processes, an overrepresentation pathway enrichment analysis was performed on each cluster using MetGenMAP [45], using rice orthologues (LOC gene ID; Additional file 1: Table S4). Table 1 describes the significantly enriched pathways of each cluster. The pathways that were significantly enriched in Clusters 1 and 2 (high in Zavitan) were mainly associated with polyamine biosynthesis and sugar degradation. The genes related to threonine and homoserine biosynthesis, phenylpropanoid biosynthesis, cell structure biosynthesis (cellulose) phospholipases, and ascorbate biosynthesis were associated with low expression in Zavitan (Clusters 3 and 4). The pathways that were significantly enriched in Clusters 5 and 6 (slightly low in Svevo) were mainly associated with the isoprenoid phosphate pathway, glycine, and glycerol degradation, brassinosteroid, jasmonic acid (13-lipoxygenase; 13-LOX) and gibberellin phytohormone biosynthesis, $\mathrm{N}$-acetylgalactosamine biosynthesis, TCA-, Calvin-, and $\gamma$-glutamyl cycles and sugar degradation. The pathways that were significantly enriched in Cluster 7 (slightly low in Zavitan) were mainly associated with glutathione, $\beta$-alanine, methionine, homocysteine, and cysteine biosynthesis, as well as gluconeogenesis, tyrosine degradation, phospholipid desaturation, and fatty acid $\beta$-oxidation. Additionally, pathways that were significantly enriched in Cluster 8 (slightly low in Chinese Spring) were mainly associated with phytohormone cytokinin biosynthesis. Together, these 


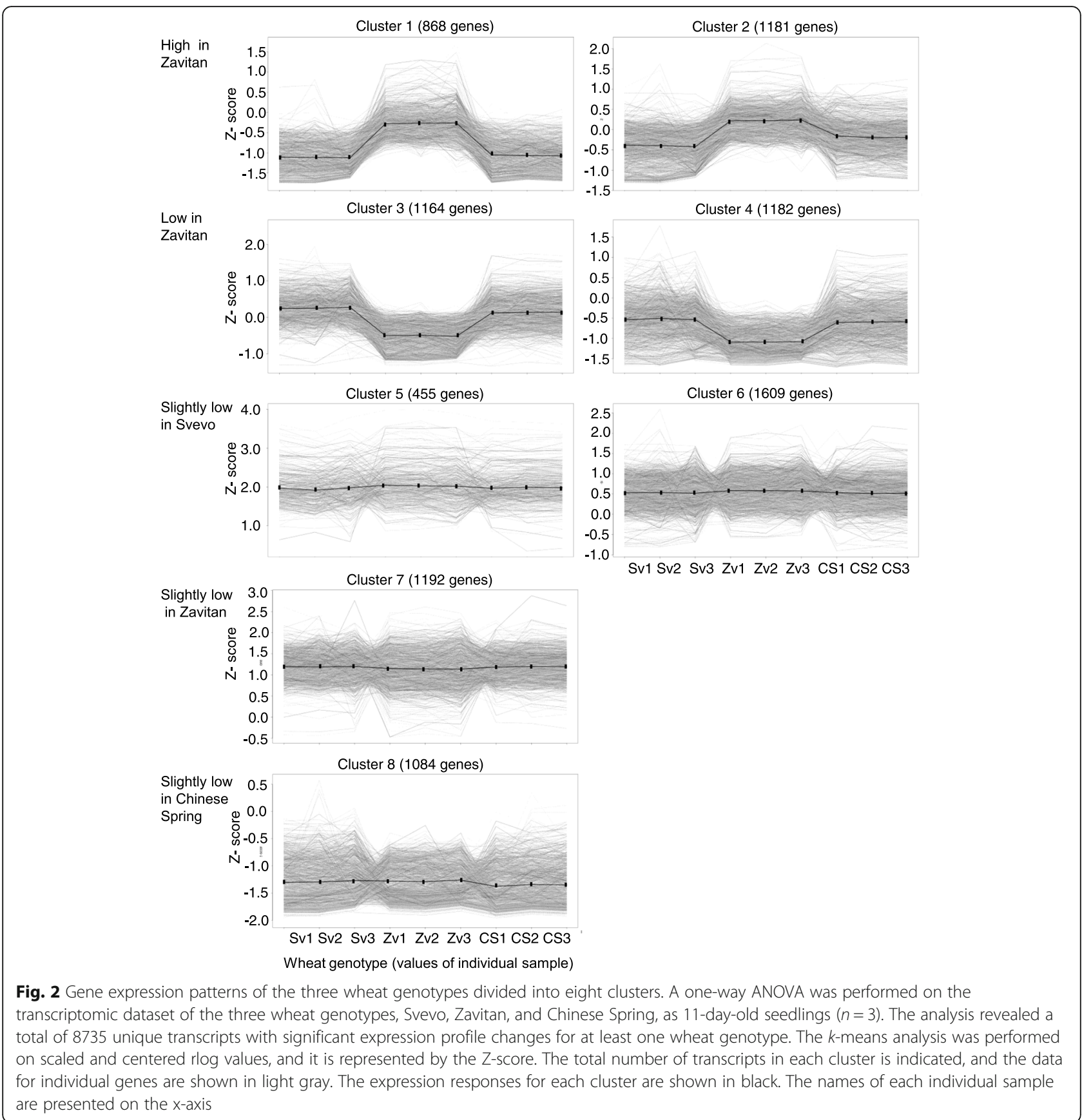

observations indicate a unique gene expression for each wheat genotype that involves diverse pathways from primary and secondary metabolites, phytohormones, oxidation state, and cell wall.

To determine which gene ontology categories were represented, we conducted a Singular Enrichment Analysis (SEA) using agriGO v2 [46], with default parameters. The International Wheat Genome Sequencing Consortium (IWGSC) database gene IDs were used as background in the SEA. In Additional file 1: Table S5, the GO terms of the biological processes of all eight clusters are presented in pairs. In Cluster 5 for example, the comparison between Zavitan-Svevo and ZavitanChinese Spring revealed biological processes related to isoprenoid biosynthesis, lipid metabolism, oxidationreduction process, photosynthesis, and tetrapyrrole metabolism. The results of Cluster 5 are partially redundant with the pathway enrichment results (Table 1), regarding the lipid/13-LOX biosynthesis and the isoprenoid biosynthesis. The functional enrichment terms in this cluster are the most consistent with the differences in defense adaptations between the three 
Table 1 Enrichment analysis of metabolic pathways significantly over-represented in the three wheat genotypes

\begin{tabular}{|c|c|c|c|}
\hline Gene expression pattern & Cluster number & Pathway Description & $P$ value \\
\hline \multirow[t]{6}{*}{ High in Zavitan } & \multirow[t]{4}{*}{1} & acyl-CoA thioesterase pathway & $1.05 \mathrm{E}-02$ \\
\hline & & sucrose degradation & $1.29 \mathrm{E}-02$ \\
\hline & & starch degradation & 1.87E-02 \\
\hline & & $\beta$-D-glucuronide degradation & 4.19E-02 \\
\hline & \multirow[t]{2}{*}{2} & superpathway of polyamine biosynthesis & 2.06E-02 \\
\hline & & $\beta$-alanine betaine biosynthesis & $3.56 \mathrm{E}-02$ \\
\hline \multirow[t]{8}{*}{ Low in Zavitan } & \multirow[t]{4}{*}{3} & threonine biosynthesis from homoserine & 2.44E-02 \\
\hline & & flavonoid biosynthesis & 2.73E-02 \\
\hline & & phenylpropanoid biosynthesis & 3.37E-02 \\
\hline & & de novo biosynthesis of pyrimidine deoxyribonucleotides & 4.06E-02 \\
\hline & \multirow[t]{4}{*}{4} & cellulose biosynthesis & 2.70E-03 \\
\hline & & trehalose degradation (high osmolarity) & 1.47E-02 \\
\hline & & phospholipases & $1.76 \mathrm{E}-02$ \\
\hline & & ascorbate biosynthesis & 2.24E-02 \\
\hline \multirow[t]{20}{*}{ Slightly low in Svevo } & \multirow[t]{7}{*}{5} & isopentenyl diphosphate biosynthesis & $3.52 \mathrm{E}-04$ \\
\hline & & glycine cleavage complex & 7.60E-03 \\
\hline & & divinyl ether biosynthesis II (13-LOX) & 1.41E-02 \\
\hline & & 13-LOX and 13-HPL pathway & 1.41E-02 \\
\hline & & brassinosteroid biosynthesis & $2.62 \mathrm{E}-02$ \\
\hline & & glycerol degradation & 3.45E-02 \\
\hline & & reductive TCA cycle & 4.88E-02 \\
\hline & \multirow[t]{13}{*}{6} & brassinosteroid biosynthesis & $1.29 \mathrm{E}-03$ \\
\hline & & UDP-N-acetylgalactosamine biosynthesis & $3.91 \mathrm{E}-03$ \\
\hline & & UDP-glucose conversion & 4.78E-03 \\
\hline & & Calvin cycle & 4.78E-03 \\
\hline & & GDP-L-fucose biosynthesis I (from GDP-D-mannose) & $5.53 \mathrm{E}-03$ \\
\hline & & NAD salvage pathway ॥ & $9.16 \mathrm{E}-03$ \\
\hline & & UDP-galactose biosynthesis & 1.10E-02 \\
\hline & & ent-kaurene biosynthesis & 1.17E-02 \\
\hline & & dTDP-L-rhamnose biosynthesis & $1.95 \mathrm{E}-02$ \\
\hline & & superpathway of GA12 biosynthesis & 2.10E-02 \\
\hline & & galactose degradation & 2.22E-02 \\
\hline & & ү-glutamyl cycle & $2.55 \mathrm{E}-02$ \\
\hline & & GDP-D-rhamnose biosynthesis & 4.59E-02 \\
\hline \multirow[t]{9}{*}{ Slightly low in Zavitan } & \multirow[t]{9}{*}{7} & glutathione biosynthesis & $1.91 \mathrm{E}-04$ \\
\hline & & $\beta$-alanine biosynthesis & $3.66 \mathrm{E}-03$ \\
\hline & & gluconeogenesis & $5.68 \mathrm{E}-03$ \\
\hline & & tyrosine degradation & $5.82 \mathrm{E}-03$ \\
\hline & & phospholipid desaturation & $1.87 \mathrm{E}-02$ \\
\hline & & fatty acid $\beta$-oxidation & $3.98 \mathrm{E}-02$ \\
\hline & & glycolipid biosynthesis & 4.11E-02 \\
\hline & & methionine biosynthesis & 4.11E-02 \\
\hline & & homocysteine and cysteine biosynthesis & 4.77E-02 \\
\hline Slightly low in Chinese Spring & 8 & cytokinins biosynthesis & 1.48E-03 \\
\hline
\end{tabular}


genotypes. Other clusters included functions such as the organic acid metabolic process, the cellular amino acid metabolic process, cell redox homeostasis and metal ion transport (Cluster 7), the oxidation-reduction process (only differentially expressed genes of Svevo vs. Chinese Spring; Cluster 6), and the phenylalanine catabolic process (only differentially expressed genes of Svevo vs. Zavitan; Cluster 3). The remaining clusters included functional enrichment terms, such as protein phosphorylation, lipid transport, and recognition of pollen.

\section{Characterization of metabolic and physiological differences between the three wheat genotypes}

Several pathways related to central metabolism, such as carbohydrate, amino, and fatty acids and the TCA cycle, showed variation in gene expression between the three genotypes (Table 1). Therefore, we performed a metabolic analysis of 11-day-old wheat seedlings using gas chromatography-mass spectrometry (GC-MS). This analysis revealed the relative levels of 72 metabolites, including amino acids, organic acids, sugars, and sugar alcohols (Additional file 1: Table S6). Table 2 shows the relative levels of 24 significantly different metabolites using a one-way-ANOVA. The results indicated that three aromatic amino acids, organic acids, and sugars were significantly lower in Svevo. Other metabolites showed no significant differences and are presented in Additional file 1: Table S6.

Both the pathway enrichment analysis of Cluster 2 (Table 1) and the GO terms of Cluster 5 (Additional file 1: Table S5) revealed that genes related to polyamine biosynthesis and the oxidation-reduction process are differently expressed between the three genotypes. Polyamines serve as substrates for oxidation reactions that

Table 2 Analysis of the central metabolites in the three wheat genotypes detected by gas chromatography-mass spectrometry (GC-MS)

\begin{tabular}{|c|c|c|c|c|c|c|c|c|c|c|c|c|c|c|c|}
\hline \multirow{3}{*}{ Class } & \multirow{3}{*}{$\begin{array}{l}\text { Metabolite (relative abundance } \\
\text { of the ion counts) } \\
\text { Aspartic acid }\end{array}$} & \multirow{2}{*}{\multicolumn{4}{|c|}{$\frac{\text { Svevo }}{\text { Average +/- SE }}$}} & \multirow{2}{*}{\multicolumn{4}{|c|}{$\frac{\text { Zavitan }}{\text { Average +/-SE }}$}} & \multirow{2}{*}{\multicolumn{4}{|c|}{$\frac{\text { Chinese Spring }}{\text { Average }+/- \text { SE }}$}} & \multicolumn{2}{|c|}{ one way ANOVA } \\
\hline & & & & & & & & & & & & & & \multirow{2}{*}{$\begin{array}{l}\text { Fvalue } \\
6.1\end{array}$} & \multirow{2}{*}{$\begin{array}{l}\begin{array}{l}P \text { value } \\
\text { (FDR) }\end{array} \\
5.0 \mathrm{E}-02\end{array}$} \\
\hline & & 9.41 & $+/-$ & 0.48 & $a b$ & 20.23 & $+/-$ & 7.60 & $a$ & 5.67 & $+/-$ & 0.87 & $b$ & & \\
\hline & Phenylalanine & 0.70 & $+/-$ & 0.07 & $b$ & 2.13 & $+/-$ & 0.77 & a & 0.59 & $+/-$ & 0.05 & $b$ & 7.6 & $3.5 \mathrm{E}-02$ \\
\hline & Tryptophan & 0.01 & $+/-$ & 0.00 & $b$ & 0.05 & $+/-$ & 0.02 & a & 0.02 & $+/-$ & 0.01 & $a b$ & 8.4 & $3.2 \mathrm{E}-02$ \\
\hline & Tyrosine & 0.02 & $+/-$ & 0.01 & $b$ & 0.10 & $+/-$ & 0.03 & $a b$ & 0.14 & $+/-$ & 0.04 & $a$ & 6.2 & $4.8 \mathrm{E}-02$ \\
\hline \multirow[t]{12}{*}{ Organic acid } & Citric acid & 5.40 & $+/-$ & 0.32 & $b$ & 17.03 & $+/-$ & 6.09 & $\mathrm{a}$ & 4.73 & $+/-$ & 0.46 & $b$ & 8.1 & $3.3 \mathrm{E}-02$ \\
\hline & Fumaric acid & 0.28 & $+/-$ & 0.02 & $b$ & 1.03 & $+/-$ & 0.28 & $\mathrm{a}$ & 0.41 & $+/-$ & 0.06 & $b$ & 11.7 & $1.4 \mathrm{E}-02$ \\
\hline & Gluconic acid & 0.14 & $+/-$ & 0.01 & $b$ & 0.99 & $+/-$ & 0.39 & a & 0.30 & $+/-$ & 0.02 & $b$ & 9.0 & $3.0 \mathrm{E}-02$ \\
\hline & Glyceric acid & 1.92 & $+/-$ & 0.11 & $b$ & 5.57 & $+/-$ & 1.88 & a & 4.46 & $+/-$ & 0.57 & $a b$ & 6.3 & $4.8 \mathrm{E}-02$ \\
\hline & Hexadecanoic acid & 3.95 & $+/-$ & 0.35 & $b$ & 12.22 & $+/-$ & 2.09 & $\mathrm{a}$ & 5.98 & $+/-$ & 1.24 & $b$ & 12.6 & $1.3 \mathrm{E}-02$ \\
\hline & Hydroquinone & 0.15 & $+/-$ & 0.01 & $b$ & 0.38 & $+/-$ & 0.11 & a & 0.14 & $+/-$ & 0.02 & $b$ & 8.3 & $3.2 \mathrm{E}-02$ \\
\hline & Malic acid & 5.51 & $+/-$ & 0.52 & $b$ & 18.82 & $+/-$ & 4.77 & a & 7.15 & $+/-$ & 0.71 & $b$ & 13.5 & $1.2 \mathrm{E}-02$ \\
\hline & Octadecanoic acid & 4.92 & $+/-$ & 0.39 & $b$ & 14.30 & $+/-$ & 2.28 & a & 7.23 & $+/-$ & 0.91 & $b$ & 18.7 & 7.2E-03 \\
\hline & Quinic acid & 4.33 & $+/-$ & 0.52 & $b$ & 13.22 & $+/-$ & 3.16 & a & 8.75 & $+/-$ & 0.93 & $a b$ & 10.6 & $1.9 \mathrm{E}-02$ \\
\hline & Saccharic acid & 0.72 & $+/-$ & 0.06 & $b$ & 2.23 & $+/-$ & 0.75 & a & 0.13 & $+/-$ & 0.01 & $b$ & 13.4 & $1.2 \mathrm{E}-02$ \\
\hline & Shikimic acid & 4.11 & $+/-$ & 0.73 & $b$ & 7.43 & $+/-$ & 2.33 & $a b$ & 9.11 & $+/-$ & 0.67 & $\mathrm{a}$ & 6.8 & $4.2 \mathrm{E}-02$ \\
\hline & 2-Oxogluconic acid & 5.29 & $+/-$ & 0.62 & $b$ & 17.44 & $+/-$ & 3.53 & $a b$ & 23.68 & $+/-$ & 5.90 & a & 6.7 & $4.2 \mathrm{E}-02$ \\
\hline \multirow[t]{6}{*}{ Sugar } & Fructose & 3.16 & $+/-$ & 0.19 & $b$ & 11.79 & $+/-$ & 3.60 & $a b$ & 20.36 & $+/-$ & 5.05 & a & 7.5 & $3.5 \mathrm{E}-02$ \\
\hline & Glucose & 3.45 & $+/-$ & 0.38 & $b$ & 11.01 & $+/-$ & 2.54 & $a b$ & 16.29 & $+/-$ & 2.56 & a & 14.4 & $1.2 \mathrm{E}-02$ \\
\hline & Maltose & 0.43 & $+/-$ & 0.02 & $b$ & 68.83 & $+/-$ & 22.33 & a & 0.65 & $+/-$ & 0.11 & $\mathrm{~b}$ & 20.2 & $7.2 \mathrm{E}-03$ \\
\hline & Ribose & 0.56 & $+/-$ & 0.05 & $b$ & 1.75 & $+/-$ & 0.60 & $\mathrm{a}$ & 2.39 & $+/-$ & 0.15 & $\mathrm{a}$ & 19.0 & $7.2 \mathrm{E}-03$ \\
\hline & Xylose & 0.15 & $+/-$ & 0.01 & $b$ & 0.39 & $+/-$ & 0.14 & a & 0.39 & $+/-$ & 0.04 & a & 7.5 & $3.5 \mathrm{E}-02$ \\
\hline & $\mathrm{N}$-acetylmannosamine & 0.37 & $+/-$ & 0.02 & $b$ & 1.06 & $+/-$ & 0.38 & a & 0.99 & $+/-$ & 0.04 & a & 8.8 & $3.0 \mathrm{E}-02$ \\
\hline Sugar acid & Galactaric acid & 0.24 & $+/-$ & 0.01 & $b$ & 0.56 & $+/-$ & 0.18 & a & 0.03 & $+/-$ & 0.01 & $b$ & 14.2 & $1.2 \mathrm{E}-02$ \\
\hline Sugar alcohol & Galactinol & 1.93 & $+/-$ & 0.21 & $b$ & 10.73 & $+/-$ & 3.63 & a & 1.90 & $+/-$ & 0.35 & $b$ & 12.1 & $1.4 \mathrm{E}-02$ \\
\hline
\end{tabular}

The metabolic profile was conducted in 11-day-old wheat leaves, and metabolites were normalized to the internal standard and presented as the relative abundance of the ion counts. The $P$ value (fold discovery rate) was calculated using one-way ANOVA analysis (Tukey HSD), and the different superscript letters indicate statistical significance (mean $\pm \mathrm{SE}, n=3-6$ ) 
produce hydrogen peroxide $\left(\mathrm{H}_{2} \mathrm{O}_{2}\right)$ both intra- and extracellularly [47]. One of the earliest signaling roles in many environmental stresses involves reactive oxygen species (ROS). As the most stable ROS, hydrogen peroxide plays a crucial role in physiological processes in plants, such as growth, development, and reproductive growth, and it is also involved in defense against pathogens and diseases [48]. We measured hydrogen peroxide in the leaves of 11-day-old plants using DAB staining (3, 3'-Diaminobenzidine). The leaves of Zavitan generated more dark brown precipitate than the other two genotypes. The sodium phosphate control treatment showed no precipitate (Fig. 3a). This suggested that the oxidative status of Zavitan is higher than Svevo and Chinese Spring.

The effect of various abiotic and biotic stresses on the photosynthetic apparatus is inevitably associated with the formation of harmful ROS $[49,50]$. In addition, both oxidation-reduction processes and photosynthetic processes were significantly represented in the GO term analysis (Additional file 1: Table S5, Cluster 5). As an indication of the differences in photosynthesis, we measured the total chlorophyll content by quantifying the levels of chlorophyll a and b [51]. As described in Fig. 3b, Zavitan leaves had significantly lower levels of total chlorophyll than Svevo and Chinese Spring leaves.

Genes related to sucrose and starch degradation were expressed at higher levels in Zavitan than in the other two genotypes (Cluster 1). Previous studies linked the effect of carbohydrate metabolism to the condition of the photosynthetic apparatus [52] and water content [53]. Therefore, we also measured the water content in the leaves, which is a critical indication of plant response to different environmental stresses [54-57]. As shown in Fig. 3c, Zavi$\tan$ leaves have significantly higher water content than Svevo and Chinese Spring leaves. The leaves' fresh, turgid, and dry weights are presented in Additional file 1: Table S7. Overall, these results support our transcriptomic analysis and show some similarities to the cultivated wheat genotypes relative to the wild emmer.

A)

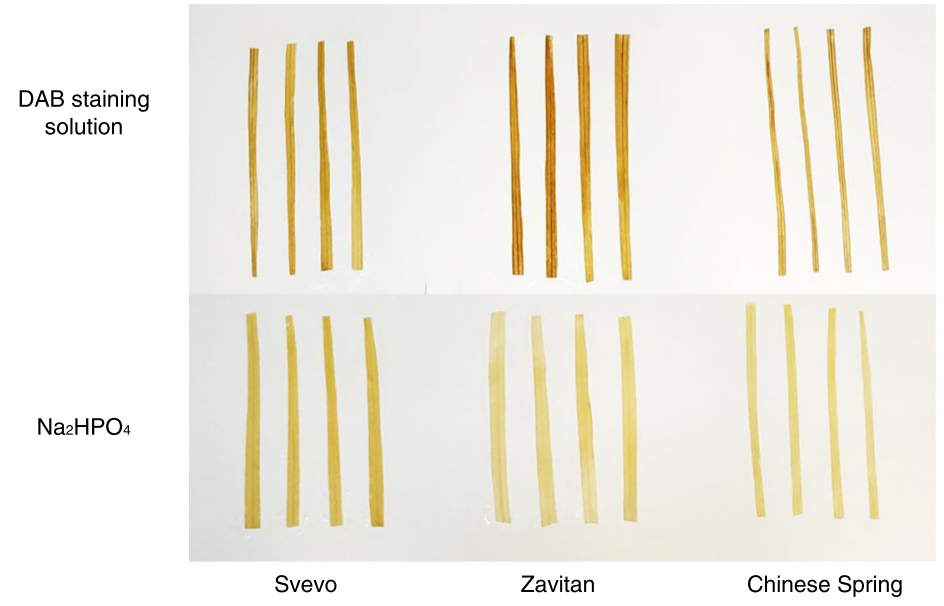

B)
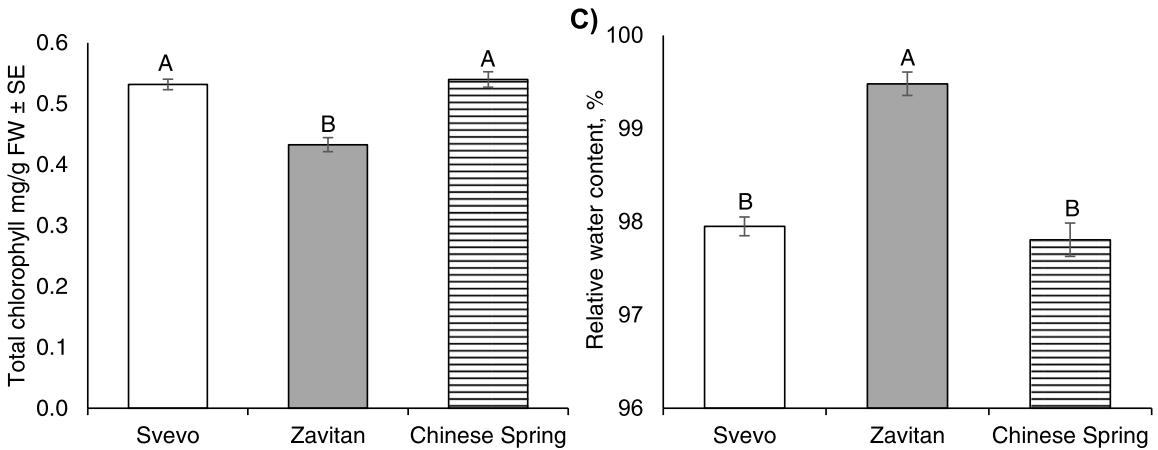

Fig. 3 Physiological characterization of the three genotypes including ROS, total chlorophyll levels, and water content. a DAB staining of hydrogen peroxide levels in the wheat leaves. Upper panel: DAB solution; lower panel: $\mathrm{Na}_{2} \mathrm{HPO} 4$ solution, which was applied as a control treatment. b Total chlorophyll content in leaves of wheat plants (mean $\pm \mathrm{SE}, n=5$ ). c The relative water content of three wheat cultivars (mean values $\pm \mathrm{SE}, n=5$ ). Different letters above the bars indicate significant differences ( $P$ value $<0.05$ ), one-way ANOVA using the Tukey-Kramer HSD test 


\section{Differences in gene expression related to chemical and physical defense adaptations}

The pathway enrichment suggested that several pathways related to plant defense mechanisms differ between the genotypes. These include the 13-LOX and 13-HPL pathway, which is related to JA biosynthesis [58], isopentenyl diphosphate biosynthesis (terpenoids) [59], both in Cluster 5, and flavonoid biosynthesis [60] in Cluster 3 (Table 1). Therefore, we further investigated the gene expression of the benzoxazinoids as chemical toxic compounds and trichomes as a physical defense mechanism. To generate a gene list, we searched the BREADWHEATCYC2.0 database (www.plantcyc.org) and the literature (the benzoxazinoid biosynthetic genes named $B x 1$ through $B x 14)[16,61,62]$. In the case of the unknown $B x$ genes in wheat ( $B x 6, B x 7$, and $B x 10-14)$, we aligned the maize protein sequences [63-65] to the wheat Ensemble Plant database (see Additional file 1: Table S8 for the full gene list). The expression values of $B x$ genes in each genotype are presented in the heatmap, and the samples are sorted by hierarchical clustering
(Fig. 4a). The heatmap indicated that the samples of the cultivated wheat Svevo were closer to Chinese Spring than to Zavitan. It also showed that some genes, such as cytochrome P450, Bx3, and $B \times 5$, were expressed at higher levels in Zavitan, while other genes, such as the downstream glucosidases and O-methyltransferases, were higher in Svevo and Chinese Spring. This suggested some similarities between Svevo and Chinese Spring regarding the benzoxazinoid biosynthesis genes.

We also compared the gene expression of trichomeformation-related genes as representative of a physical barrier [66, 67]. To generate a gene list, we searched the literature and found some evidence for trichome formation genes in rice, including Glabrous Rice 1, encoding a homeodomain protein [68], and the pubescence gene GL6 [69]. We also identified maize protein homologs, including i) HD-ZIP IV transcription factor OCL4, which is necessary for trichome patterning [70]; ii) UMC1273, which is a protein trichome birefringence-like 39; iii) UMC1601 protein trichome birefringence-like 28; iv) AY110056 protein trichome birefringence-like 26; and v)

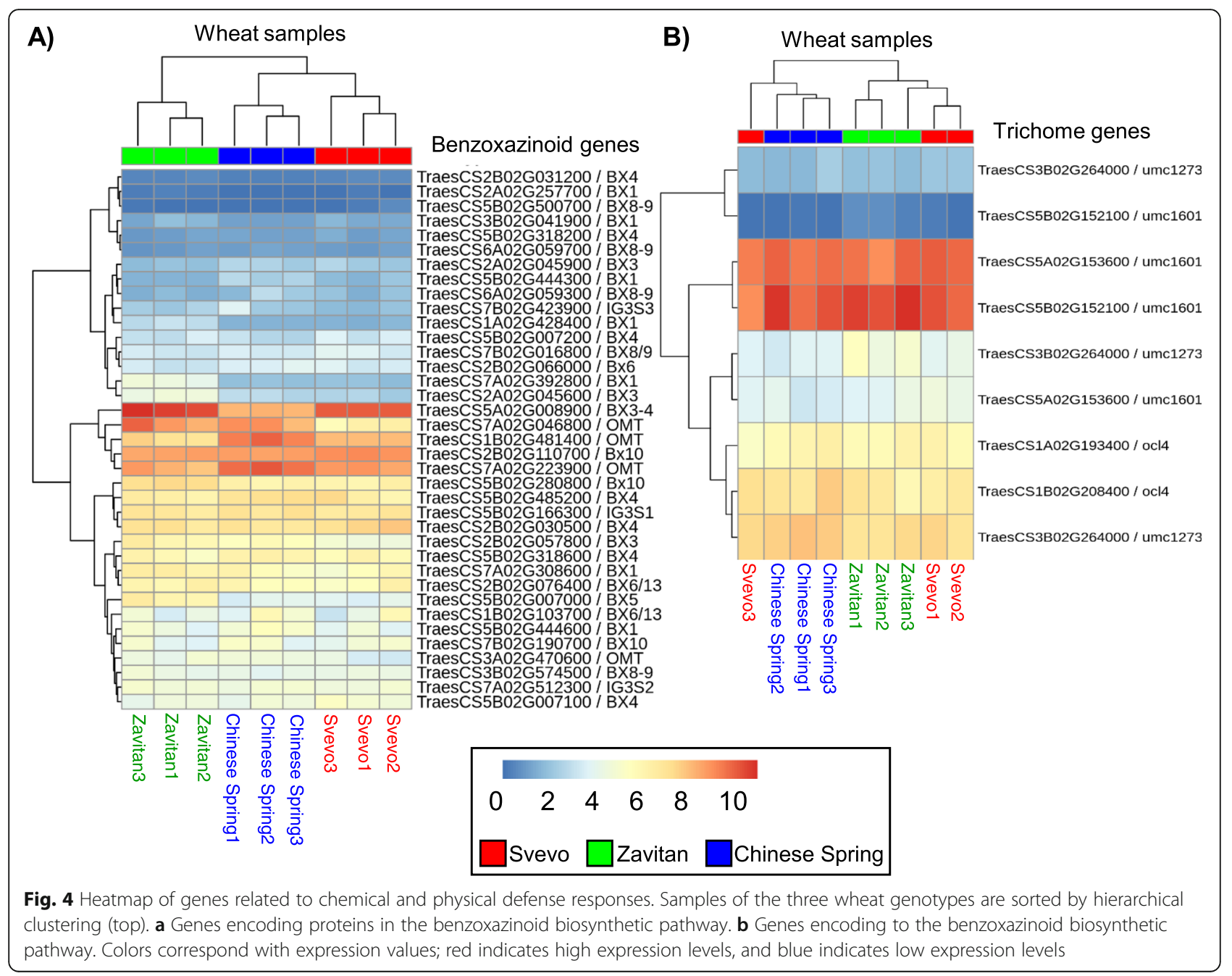


prm5 (powdery mildew resistant protein 5; (see Additional file 1: Table S9 for the full gene list). The expression values of the trichome formation genes in each genotype are presented in the heatmap, and the samples are sorted by hierarchical clustering (Fig. 4b). The heatmap did not show a clear pattern, as two Svevo samples were clustered with Zavitan and one was clustered with Chinese Spring.

\section{Quantification of changes in benzoxazinoid levels during plant development}

We focused our analysis of defense metabolites on benzoxazinoids (BXDs), which are major deterrent compounds and have been demonstrated to play a role in chemical defense in wheat leaves [71, 72]. The BXDs are abundant in wheat seedlings and show the highest activity in plants at the juvenile stage [14-16]. In this experiment, we measured, by HPLC-UV, the levels of BXDs in young wheat plants: 11,15 , and 18 days after germination. Overall, three BXD compounds were detected and identified, including 2,4-dihydroxy-7-methoxy1,4-benzoxazin-3-one, 4-dihydroxy-7,8-dimethoxy-1,4-benzoxazin-3-one glucoside ( $\left.\mathrm{DIM}_{2} \mathrm{BOA}-\mathrm{Glc}\right)$, and 2-hydroxy4,7-dimethoxy-1,4-benzoxazin-3-one glucoside (HDMBOA-Glc) as presented in Fig. 5a-c. These compounds were further annotated by comparing the pattern of their fragment using UPLC-QToF-MS and previous studies (Additional file 1: Table S10 [73, 74]; ). All compounds were detected in at least one sampling time point, in the domesticated wheat genotypes, while they were below detection levels in the wild emmer Zavitan. The genotypes Svevo and Chinese Spring showed the highest levels of DIMBOA on day 11, which gradually declined until day 18 . In Chinese Spring, DIMBOA levels declined more rapidly than in Svevo. DIM ${ }_{2}$ BOA-Glc levels showed different accumulation patterns than DIMBOA, as the highest levels were detected on day 15 when Chinse Spring was much higher than Svevo. Overall, the twoway-ANOVA of both DIMBOA and DIM $_{2}$ BOA-Glc demonstrates significant differences in time (day after germination) and in the two wheat genotypes. The HDMBOA-Glc levels were much lower than the other two BXD compounds and only detected in Chinese Spring 11 and 18 days after germination and only at 18 days after germination in Svevo leaves.

\section{Calculating the trichome density}

To explore the physical adaptation of wheat plants against aphid invasion, we evaluated the trichome density on the leaf edge and surface as a physical barrier (Fig. 6). As presented in Fig. 6a, the two-way-ANOVA suggests a significant difference in trichome number on the edges between the three wheat genotypes ( $\mathrm{F}$ genotype ${ }_{(2224)}=498.36, \quad P$ value $\left.<0.0001\right)$, the day after germination $\left(\mathrm{F}_{\text {time }}(2224)=5.30, P\right.$ value $\left.=0.0056\right)$, and a cross-effect ( $\mathrm{F}$ genotype"time (2224) $=3.05, P$ value $=0.0178$ ). The highest number of trichomes on the leaf edges was in Zavitan, while Svevo and Chinese Spring had a similar number of trichomes, except 18 days after germination, when Chinese Spring showed the lowest trichome number. The number of trichomes slightly increased over time, mainly on Zavitan and Svevo. In Fig. 6b, the trichome density on the leaf surface is presented. The two-way-ANOVA suggests a significant difference in trichome number on the surface between the three wheat genotypes (F genotype $(2372)=268.32, P$ value $<0.0001)$, the day after germination $\left(F_{\text {time }}(2372)=\right.$ 15.99, $P$ value $<0.0001)$, and a cross-effect (F genotype"time ${ }_{(2372)}=8.70, P$ value $\left.<0.0001\right)$. The highest number of trichomes on the leaf surface was in Zavitan, while Chinese Spring possessed the lowest trichome number. Images of the trichomes demonstrated that the trichomes are also different in their lengths and angles. As shown in Fig. 6c, the trichome lengths observed on the leaf surfaces of Zavitan and Chinese Spring were longer than those on Svevo. Additionally, the trichomes on the edges faced one direction only on Zavitan and Chinese Spring, while on Svevo, they faced both directions. Altogether, this suggested that Zavitan has more trichomes as a physical barrier than the other two genotypes.

\section{Evaluation of aphid reproduction on different wheat genotypes}

The aphid performance on wheat seedlings infested with aphids for $96 \mathrm{~h}$ was evaluated at two time points: 15 and 18 days after germination. The two-way ANOVA suggested a significant difference in the aphid progeny between the three wheat genotypes ( $\mathrm{F}$ genotype $(2,45)=$ $20.60, P$ value $<0.0001)$, the day after germination ( $F$ time $(1,45)=161.93, P$ value $<0.0001)$, and a cross-effect $\left(F_{\text {gen- }}\right.$ otype"time $(2,45)=4.24, P$ value $=0.021)$, indicating the effect of both genotype and age (day after germination) on aphid reproduction (Fig. 7). In the two measurements (15 and 18 days after germination), the Chinese Spring genotype was more aphid-resistant than the other two genotypes, while Zavitan and Svevo were not significantly different. Additionally, 18-day-old wheat seedlings were more susceptible to aphids than the 15-day-old plants.

\section{Discussion}

In this research, we selected three wheat genotypes, including wild emmer, durum, and bread wheat, to address the fundamental question of the effect of domestication on plant resistance against aphids. To understand the overall gene levels and the differential gene expression between genotypes [75], we compared the transcriptomes of 11-day-old seedlings of the three genotypes. 

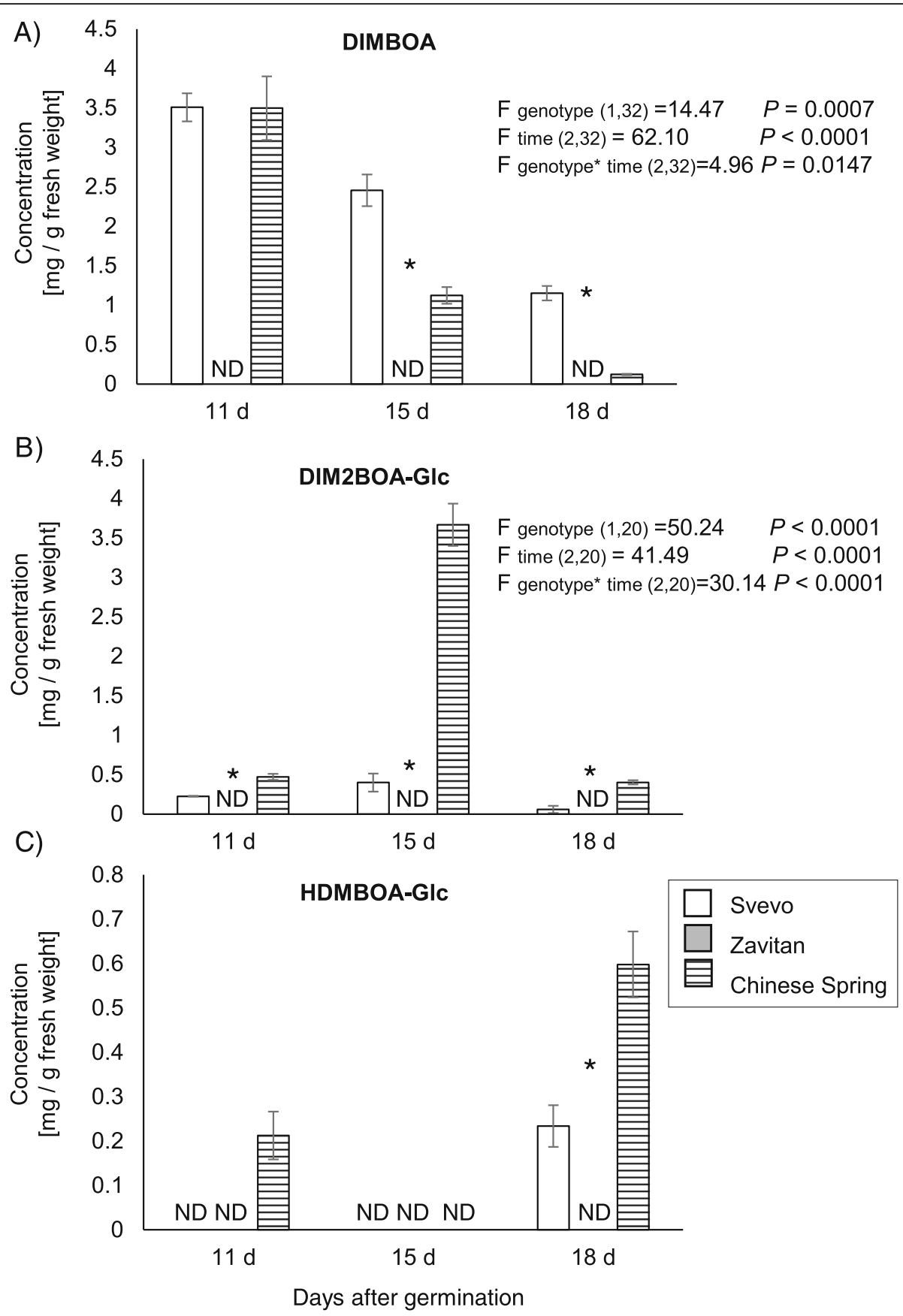

Fig. 5 The benzoxazinoid levels in three selected wheat genotypes at 11, 15 and 18 days after germination. Leaves were harvested 11, 15, and 18 days after germination, and the samples were analyzed using HPLC-UV (mean $\pm \mathrm{SE}, n=2-6)$. A statistics Student's t-test $(P$ value $<0.05)$ was performed on the Svevo and Chinese Spring genotypes. a 2,4-dihydroxy-7-methoxy-1,4-benzoxazin-3-one (DIMBOA), b 2,4-dihydroxy-7,8dimethoxy-1,4-benzoxazin-3-one glucoside (DIM $\mathrm{B}_{2} \mathrm{BOA}$-Glc), c 2-hydroxy-4,7-dimethoxy-1,4-benzoxazin-3-one glucoside (HDMBOA-Glc). The Student's t-test $(P$ value $<0.05)$ was performed at each time point, and the two-way analysis of variance (ANOVA) tested between genotypes and sampling time. ND: not detected

While the PCA plot based on the transcriptomic data suggested a unique pattern for each genotype (Fig. 1), the heatmap of the differentially expressed genes $(8735$ unique transcripts) indicated a higher similarity between the domesticated genotypes than the wild emmer wheat
(Additional file 2: Figure S2). This pattern was similar when we compared the gene expression of specific biosynthetic genes of the benzoxazinoid pathway (Fig. 4). The similarity between Svevo and Chinese Spring is supported by a recent study that compared the exome of 
A)

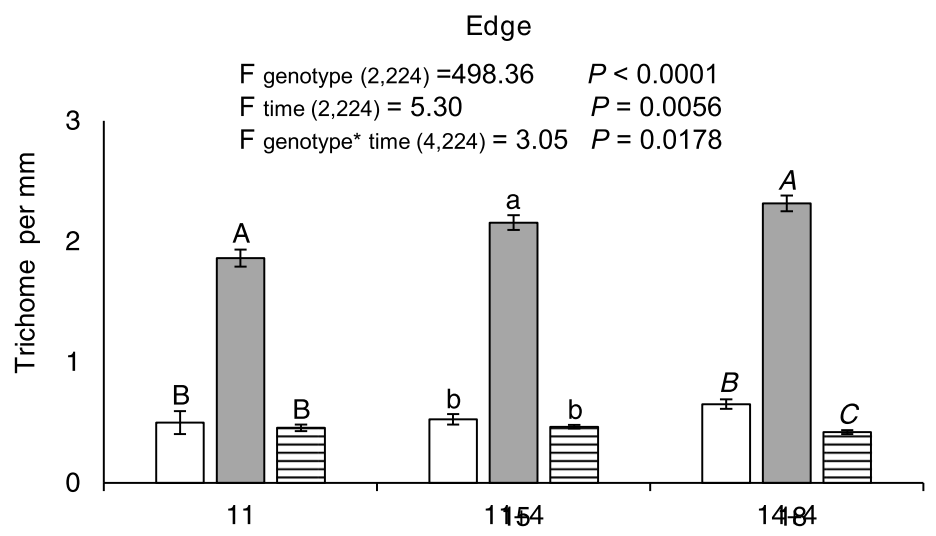

B)
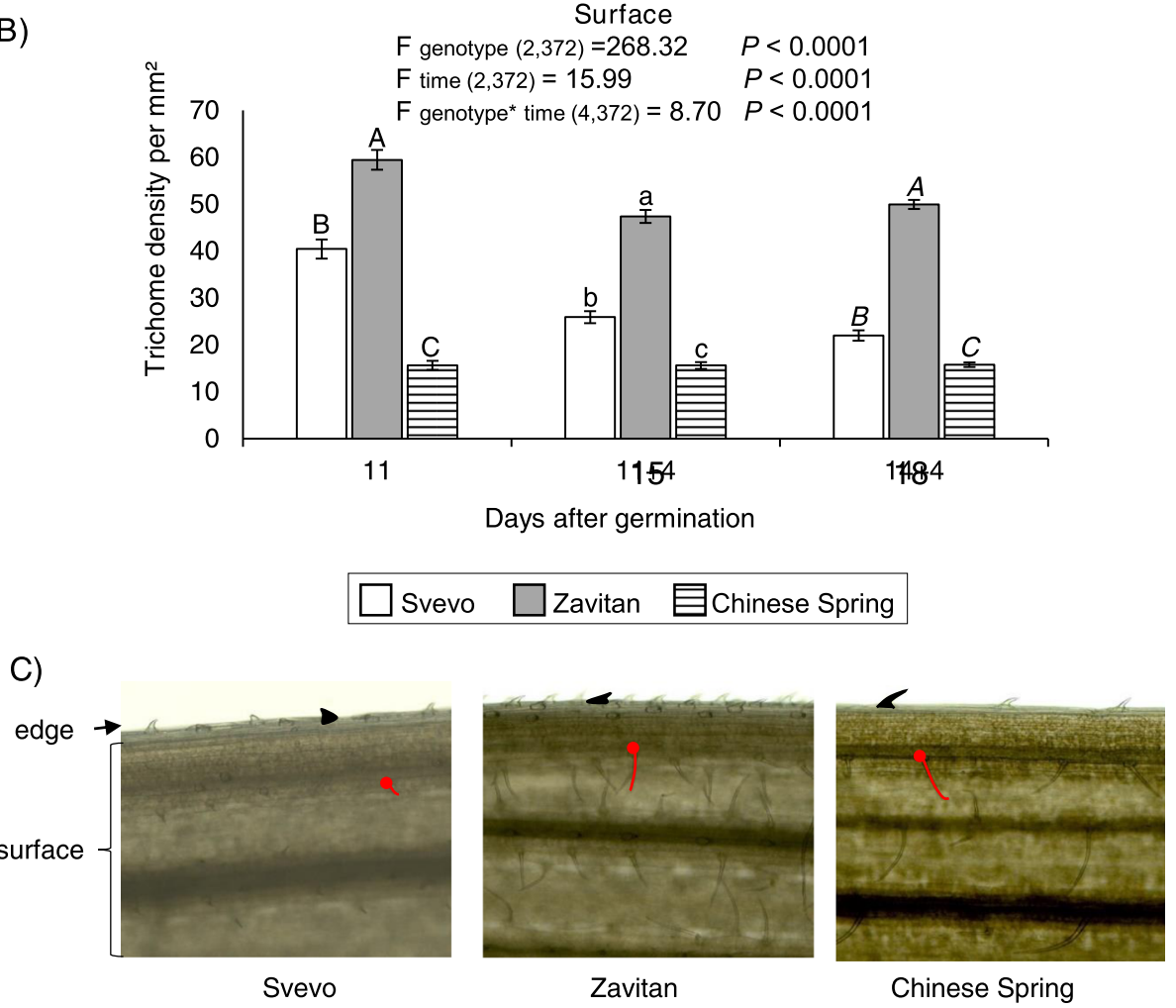

Fig. 6 Trichome density on wheat seedlings at 11,15 and 18 days after germination. Bars represent the average number of edge trichomes (a) and the density $\pm \mathrm{SE}$ of surface trichomes (b) (mean $+/-\mathrm{SE}, n=6-8$ ). Different letters above the bars indicate significant differences, using ANOVA followed by Tukey's HSD test separately for each sampling time. A summary table of the two-way ANOVA results is shown at the top. The inferior numbers indicate the degree of freedom and the total number of samples used for the test. c Images of leaf epidermis showing trichome length and direction (0.6 squared $\mathrm{mm}$ area of the leaf)

approximately 500 wheat genotypes and suggested that wild emmer wheat is the progenitor of the A and B subgenomes of all the modern tetraploid and hexaploid genotypes. The T. durum lineage was found to be the most likely ancestor of the bread wheat cultivated germplasm [20]. The similarity between Svevo and Chinese Spring might be due to a "domestication bottleneck" [21-23].

A previous study that explored the variation between 19 hexaploid bread wheat pangenomes reported that genes involved in the response to environmental stress and defense against biotic stress were variable between the genomes [76]. Similarly, in our results, several enriched functional genes involved in the response to environmental stress and defense responses are variable between the three genotypes, including polyamine biosynthesis and 13-lipoxygenase, which are the first enzymatic steps of the phytohormone, jasmonic acid (Table 1). Additionally, the over-representation pathway 

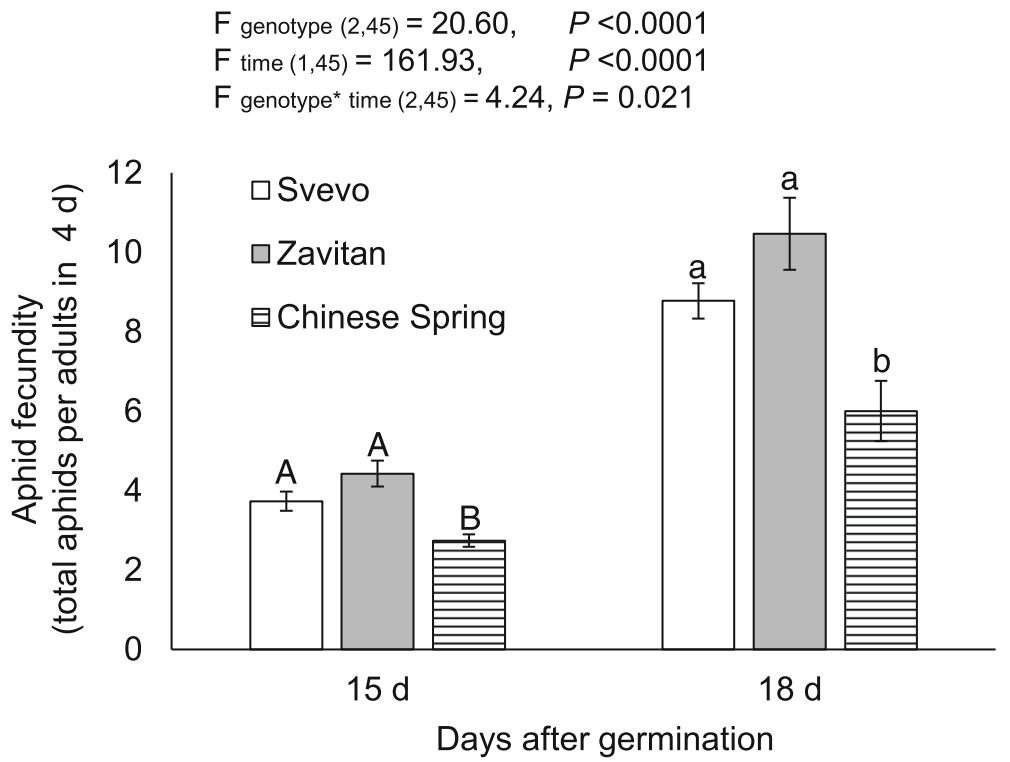

Fig. 7 Aphid reproduction on three wheat genotypes at 15 and 18 days after germination. The total number of R. padi was counted after $96 \mathrm{~h}$ of infestation at two time points: 15 and 18 days after germination (mean $\pm \mathrm{SE}, n=5-10$ ). The letters above the bars indicate significant differences between genotypes using a one-way analysis of variance (ANOVA) followed by Tukey's HSD test (separate for each time point). A summary table of the two-way ANOVA results is shown at the top. The inferior numbers indicate the degree of freedom and the total number of samples used for the test

enrichment analysis demonstrated that genes associated with amino acid metabolism and the biosynthesis of carbohydrates, cell structures, fatty acids and lipids, phytohormones, and specialized metabolites were significantly different between the three genotypes. These observations indicated the major differences in the basal gene expressions between the genotypes. This was supported by several experiments where we measured the water content (Fig. 3c) and primary metabolites of 11-day-old leaves (Table 2). The main results suggested that Zavitan has higher levels of amino acids, organic acids, and sugars than the other two genotypes.

A recent study suggested that domesticated wheat has maintained its defense traits against specialized herbivores that have coexisted with the crop throughout its domestication, but that it is less efficient against generalist herbivores [31]. We compared the reproduction of the $R$. padi aphid on the three wheat genotypes (Fig. 7), which is among the most economically important aphid associated with a host range of well over 100 species [77, 78]. Our results show that the wild emmer, which possessed a high number of trichomes and had benzoxazinoid levels below detection, is more susceptible to the $R$. padi aphid than Chinese Spring (Figs. 5, 6 and 7). Zavi$\tan$ was also more susceptible to the $R$. maidis aphid then Svevo [30]. In contrast to our results, a previous study by Migui and Lamb (2003) tested 41 accessions of wild and cultivated wheat in the field for resistance to three species of aphids, including $R$. padi. The results showed that the highest aphid resistance was in the diploid species and the lowest was in the hexaploid species [35]. This discordance may arise from accession-specific differences or may be due to the experiment being performed on mature wheat plants in field conditions, compared to young seedlings under controlled conditions (Additional file 2: Figure S1). This was supported by another study that suggests that the differences in aphid preference depend on the plant's developmental stage in the field, compared to seedlings in the laboratory [79].

In wheat, genes encoding defense mechanisms are found in hexaploid bread wheat (genome BBAADD), tetraploid wheat (genome BBAA), and in the three diploid progenitors of hexaploid wheat (genomes $\mathrm{AA}, \mathrm{BB}$, and $\mathrm{DD})[16,80]$, while several of the enzyme steps are not yet identified. A comparison between the transcript levels from the three subgenomes in hexaploid wheat indicated that the homoeologs on the $\mathrm{B}$ subgenome are the main contributors to the benzoxazinoid biosynthesis pathway, especially in shoots $[16,81]$. It was suggested that gene expression in diploids and tetraploids are far more varied than in the hexaploid population, indicating that the former species likely encode a greater allelic variation that, in turn, could facilitate breeding for pest resistance [82]. In this research, $B x$ gene expression was detected in all three genotypes, while the two domesticated wheat genotypes showed a closer pattern of gene expression and BXD levels than the wild emmer (Fig. 4a). 
The BXDs are a diverse class of specialized metabolites, which are mainly known for their deterrent functions. They are known to have a crucial effect on plant resistance to insects such as aphids [71, 83, 84], chewing herbivores [85-87], fungal infection [88], and other insects, diseases and weeds [89]. A recent study reported that the molecular functions of the BXDs are diverse beyond their toxicity. It was suggested that the BXDs function in shaping the root microbiome by selectively attracting the plant-beneficial rhizobacterium Pseudomonas putida [90, 91], and are also used as iron chelators [92]. Also, it has been estimated that naturally occurring DIMBOA may govern a physical defense mechanism against aphid feeding by the accumulation of callose [93]. Furthermore, it was reported that in maize, plant-aphid infestation caused secretion into the apoplast of DIMBOA-Glc, but not HDMBOA-Glc [71], which may indicate a unique function of DIMBOA-Glc. Our results indicated that the domesticated bread wheat Chinese Spring, which showed the lowest amount of aphid progeny, possesses a varied array of BXDs, including DIMBOA and DIM $_{2} \mathrm{BOA}-$ Glc, and HDMBOA-Glc (Fig. 5).

Interestingly, the total chlorophyll and chlorophyll a and $b$ levels were clustered together with the amount of DIMBOA measured at 11 days (Fig. 8). Previous studies revealed a new function of BXDs as iron chelators in the roots $[94,95]$. In plants, iron is an essential micronutrient that functions as a redox-active metal in many metabolic processes, including photosynthesis, mitochondrial respiration, nitrogen assimilation, hormone biosynthesis, and the production and scavenging of ROS [96]. Iron-deficient bread wheat plants exhibit significantly lower chlorophyll content and chlorosis, as well as low iron concentrations in leaves and grains [97]. Our results suggest that DIMBOA may play a role in ironchelating in the leaves. Therefore, high levels of DIMBOA (as found in Svevo and Chinese Spring) may determine the chlorophyll levels or other processes that can affect photosynthesis. However, this requires further investigation.

BXDs are constitutively produced in young plants [14-16], and tend to decline as the plant ages [98]. Our results showed that aphid progeny numbers increased over time, while BXD levels decreased (Figs. 5, 7, and 8). The leaf surface is the first defense barrier against insects; it includes trichomes, thorns, silica, and wax $[8$, 99, 100]. Trichomes are used as a physical defense by disturbing herbivore movement, development, and oviposition, while glandular trichomes are used for exudate storage and secretion [101]. The surface density of trichomes and their dispersal on the leaf edges were not directly proportional to the number of aphid progeny. This suggests higher effectiveness of the chemical defenses compared with the physical defensive barrier. Additionally, the metabolic profile and water content indicated that 11-day-old Zavitan seedlings had higher water content, as well as higher levels of some amino acids, organic acids, and sugars, than the cultivated wheat genotypes. This lack of chemical defense and better water and nutrient status may be beneficial for aphid reproduction on Zavitan relative to the domesticated wheat.

\section{Conclusions}

In this study, we combined transcriptomic, metabolomic and physiologic approaches to better understand the differences in wheat defense mechanisms. Our results suggest that benzoxazinoids provide a better defense mechanism than trichomes against $R$. padi aphids. Comparisons of significant gene expression, phenotypic characterization, and the chemical defense and physical responses indicated a higher similarity between the domesticated wheat genotypes than between either of them and the wild emmer. This suggested that under insect pressure, wheat plants might have undergone evolutionary convergence, which resulted in similarities in defense mechanisms via the biosynthesis of defense metabolites and, to a lesser extent, trichome formation.

\section{Methods}

\section{Wheat genotypes}

For this study, three wheat genotypes were selected: two tetraploids (Triticum turgidum) and a hexaploid (Triticum aestivum). The tetraploid wheat genotypes included: wild emmer wheat Zavitan (Triticum turgidum ssp. dicoccoides) $[102,103]$ and the durum wheat of Italian origin, Svevo (Triticum turgidum ssp. durum) $[103,104]$. The hexaploid wheat was genotype Chinese Spring, which is widely used as a standard for wheat cytogenetic research $[105,106]$. All plant material has been characterized and provided by Prof. Assaf Distelfeld (Tel Aviv University, Israel).

\section{Plant growth conditions}

Wheat seedlings were grown on moistened HR2 (soil mix). Wheat seeds were planted $1.5-2 \mathrm{~cm}$ deep in 330 $\mathrm{cm}^{3}$ individual plastic pots and placed in a growth room. The growth room was maintained under a controlled light regime of a 16-h-light and 8-h-night photoperiod at a constant room temperature of $26^{\circ} \mathrm{C}$, a relative humidity of $63 \%$, and a $250-350 \mu \mathrm{mol}$ photon $\mathrm{m}^{-2} \mathrm{~s}^{-1}$ light intensity from a $3000 \mathrm{~lm}$ LED (LG-06A-12-364,000 k) at a distance of $40 \mathrm{~cm}$ from the light source (measured from the top of the plastic pot). 


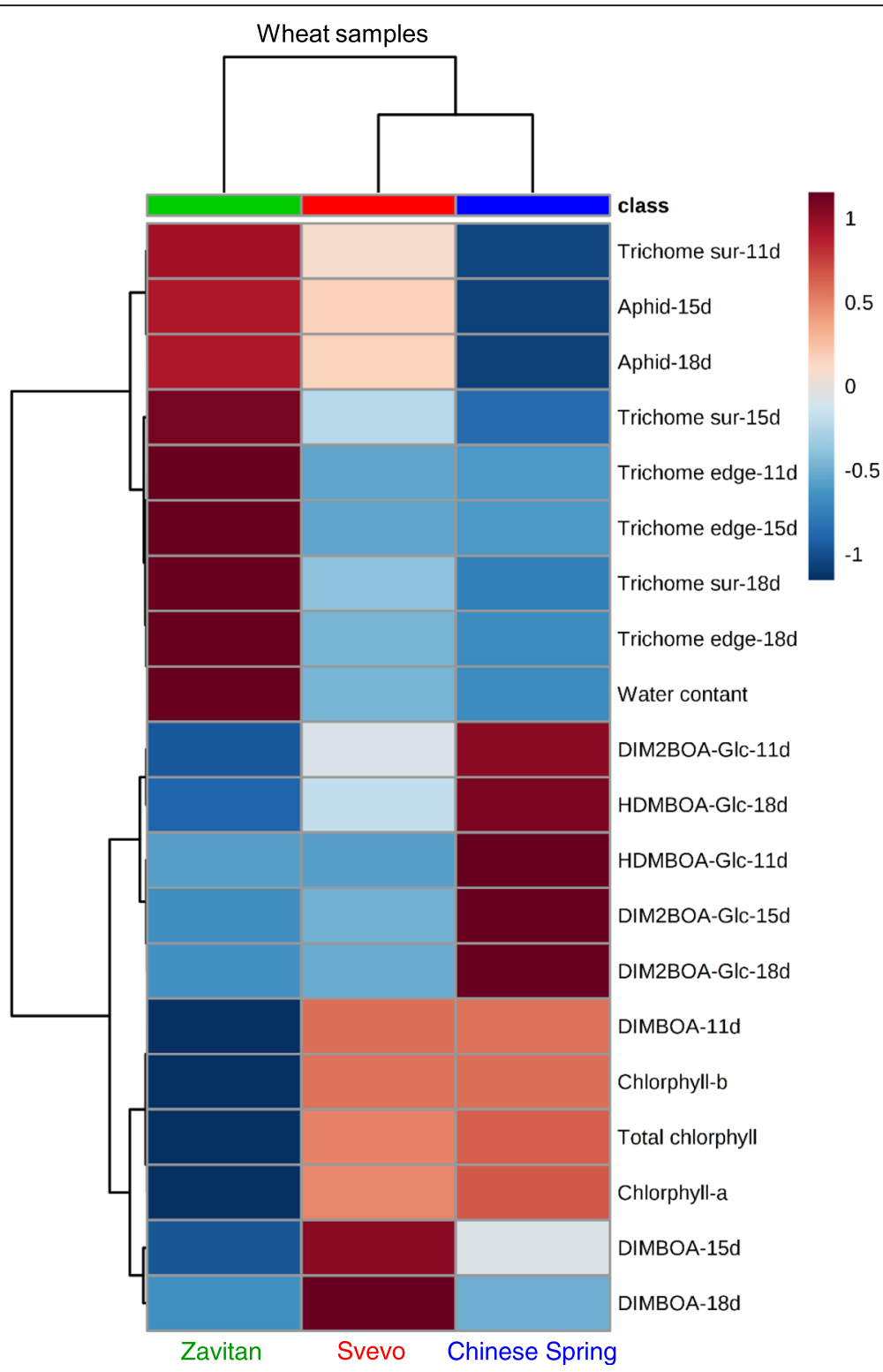

Fig. 8 A summary heatmap of the physiological parameters and defense data used in this study. All the results were included besides the GC-MS primary metabolites due to a large amount of data. The Euclidean distance with Ward's minimum variance method was designed using the default parameters of the MetaboAnalyst software. Colors correspond with concentration values (autoscale parameters); red indicates high levels, and blue indicates low levels

\section{Aphid bioassays}

Bird cherry-oat aphids (Rhopalosiphum padi) were collected in the field and identified, and the colony was maintained on two-week-old wheat plants, a Triticum aestivum variety named Rotem (Agridera Seeds \& Agriculture LTD, Israel). The colony was grown under a 16-h-light/8-h-dark photoperiod at a constant room temperature of $25^{\circ} \mathrm{C}$. For the insect bioassay, ten adult R. padi aphids (approximately 7-10 days old) were confined to the upper part of the second leaf of a seedling (11- and 14-day-old wheat) using clip cages $(4.5 \mathrm{~cm}$ in diameter). To reduce variation in aphid age (which may affect reproduction), we applied ten aphids to each cage. Aphid progeny was calculated by counting the total number of aphids (adults and nymphs) after $96 \mathrm{~h}$ of infestation and dividing by ten (the number of adult aphids used in the experiment).

RNA extraction, transcriptome sequencing, and analysis Leaf samples were collected from the top of the second leaf. Tissue samples from two 11-day-old plants were combined into one experimental replicate, and three replicates were collected for each genotype. Total RNA was extracted using an SV Total RNA Isolation Kit with 
on-column DNaseI treatment (QIAGEN). The purified RNA was quantified, and $2.5 \mu \mathrm{g}$ of each sample was used for next-generation sequencing using an Illumina HiSeq 4000 instrument with a 150 bp paired-end read length conducted by the GeneWIZ Company (www.genewiz. com). Quality control was performed using FASTQC and adapters, and low-quality sequences were trimmed and removed using Trimmomatic v0.36. Mapping was performed using a STAR aligner v2.5.2b against the Triticum aestivum reference genome v1.1 [38]. Reads aligning to exons were retrieved using Subread v1.5.2. For differential gene analysis, DESeq2 v1.22.2 [107] was used to perform a likelihood ratio test (LRT) to evaluate multiple genotypes at once (adjusted $p$-value $<0.05$ ). The IWGSC refseq v1.0 high confidence (HC) functional annotation was used without sequences from the D genome, as this genome is not present in the wild and cultivated tetraploid wheat, and from the unknown genome. Next, DESeq2 was performed on the statistically significant genes from the LRT, and a regularized log was applied to the results. MetGenMAP was used to perform a pathway enrichment analysis [45], using rice ortholog IDs, which were converted from Phytozome wheat transcript IDs. In order to convert between IWGSC and Phytozome wheat transcript IDs, a reciprocal BLASTp comparison was performed, and only transcript IDs with mutual hits were retrieved. The MetGenMAP analysis allowed us to associate specific biochemical pathways with the differentially expressed genes found in our study. AgriGO v2 was used to perform a functional enrichment analysis of differentially expressed genes. This analysis identifies enriched gene ontology (GO) terms by comparing a query list of gene identifiers and their corresponding GO terms, with a background population list from which the query list was derived. The background list of genes and GO annotations was extracted from the International Wheat Genome Sequencing Consortium (IWGSC) database. The IWGSC is an international collaboration of 2400 members, which has produced a high-quality sequencing and annotation of the T. aestivum genome $[108,109]$.

\section{Benzoxazinoid extraction, analysis, and identification}

Wheat tissue was collected from the top of the second leaf and ground to a fine powder under liquid nitrogen. Then, the frozen powder was weighed, and the 1:10 (w: v) ratio of extraction solvent contained $80 \%$ methanol ( $0.1 \%$ formic acid). The mix was vortexed briefly; then, the tubes were shaken for $40 \mathrm{~min}$ at $4{ }^{\circ} \mathrm{C}$ and centrifuged for $5 \mathrm{~min}$ at $14,000 \mathrm{~g}$. Filtration was performed by centrifuging the samples on a $0.22-\mu \mathrm{m}$ filter plate (EMD Millipore Corp., Billerica, MA, USA) at $3000 \mathrm{~g}$ for $5 \mathrm{~min}$ $[74,110,111]$. The extracted mixtures were covered with a WebSeal Mat and kept at $10^{\circ} \mathrm{C}$. Samples were injected into a DIONEX UltiMate 3000 high-performance liquid chromatography (HPLC) system using a C18 reversephase Hypersil GOLD column $(3 \mu \mathrm{m}$ pore size, $150 \times$ $4.60 \mathrm{~mm}$; Thermo Fisher Scientific, Germany). The column oven temperature was $40{ }^{\circ} \mathrm{C}$ and the UV-VIS absorbance spectra was at 190-400 nm. For BXD metabolite separation, a gradient of water $(0.1 \%$ formic acid $)$ (solvent A) and acetonitrile ( $0.1 \%$ formic acid) (solvent B) with a flow rate of $1 \mathrm{ml} \times \mathrm{min}^{-1}$ was used. The following linear gradient was used: 0 to $10 \mathrm{~min}$, gradient from 5 to $55 \% \mathrm{~B} ; 10$ to $13 \mathrm{~min}$, gradient from 55 to $100 \% \mathrm{~B} ; 13-14 \mathrm{~min}$, gradient from 100 to $5 \%$; and 14 18 min, 5\% solvent B. Chromeleon software (Thermo Fisher Scientific Inc.) version 7.2 was used for system control and data acquisition. For benzoxazinoid quantification, we compared the chromatograms with the authentic standards and plant crude extract. DIMBOA and DIBOA commercial authentic standards were used (Toronto Research Chemicals, Toronto, Canada). In addition, two crude extracts were used: i) a mix of DIMBOA-Glc:DIM ${ }_{2}$ BOA-Glc in a ratio of $81: 19$, respectively, and ii) a mix of HDMBOA-Glc: $\mathrm{HDM}_{2} \mathrm{BOA}$ Glc in a ratio of $86: 14$, respectively. Calibration curves were calculated by running authentic standards and crude extracts in different concentrations ranging from $0.5-50 \mu \mathrm{g} / \mathrm{ml}$. The peak area of each compound was measured using Chromeleon software, and the final concentration was normalized to $\mathrm{mg}$ per gram fresh weight. Only three BXDs were detected in this analysis, namely DIMBOA, DIM ${ }_{2}$ BOA-Glc, and HDMBOA-Glc. The UV spectra of the three BXDs are presented in Additional file 2: Figure S3 and Additional file 1: Table S11.

For accurate mass identification of the BXDs, $5 \mu \mathrm{l}$ of $10 \mu \mathrm{g} / \mathrm{ml}$ authentic standards and crude extracts were injected onto an ultra-performance liquid chromatographyquadrupole time-of-flight mass spectrometer (UPLCQToF-MS) system equipped with an ESI interface (Waters MS Technologies, Manchester, UK), ran in negative and positive ion modes. Chromatographic separation was carried out on a C18 column $(100 \mathrm{~mm} \times 2.1 \mathrm{~mm}, 1.7 \mu \mathrm{m})$, while the column was maintained at $40^{\circ} \mathrm{C}$, and autosampler was maintained at $10^{\circ} \mathrm{C}$. For lock mass calibration, analyses were performed using leucine enkephalin at a concentration of $0.4 \mathrm{ng} / \mathrm{L}$, dissolved in $50 \%$ acetonitrile and $0.1 \%$ formic acid. The MS conditions were set essentially as described previously [112]. The sample ran in a gradient program including the mobile phase consisted of 95\% water: $5 \%$ acetonitrile and $0.1 \%$ formic acid (solvent $\mathrm{A}$ ), and $0.1 \%$ formic acid in acetonitrile (solvent B), in a flow rate of $0.5 \mathrm{ml} / \mathrm{min}$, and the scans were repeated for $15 \mathrm{~min}$ in a single run as described previously [113]. For system control and data acquisition, MassLynx software (Waters) version 4.1 was used. For benzoxazinoid fragmentation patterns, we compared the chromatograms with the authentic standards 
of DIMBOA (Toronto Research Chemicals, Toronto, Canada), DIM $_{2}$ BOA-Glc, and HDMBOA-Glc from a plant crude extract and with previous publications [73, 74, 114]. The annotations of BXDs, DIMBOA, DIM ${ }_{2}$ BOA-Glc and HDMBOA-Glc, and their fragmentation patterns are presented in Additional file 1: Table S10.

\section{Metabolic analysis using gas chromatography-mass spectrometry (GC-MS)}

For metabolite extraction, $200 \mathrm{mg}$ of ground frozen plant tissue was mixed with $1 \mathrm{ml}$ of pre-cooled extraction solvents containing 55\% methanol: 23\% chloroform: $22 \%$ Milli-Q fileted water (Millipore, Merck), and $200 \mu \mathrm{l}$ of 1 $\mathrm{mg} / \mathrm{ml}$ ribitol and $\mathrm{D}$-sorbitol ${ }^{13} \mathrm{C}_{6}$ as internal standards. The samples were briefly vortexed, incubated in a thermomixer at $1000 \mathrm{rpm}$ for $10 \mathrm{~min}$ at $25^{\circ} \mathrm{C}$, followed by $10 \mathrm{~min}$ of sonication; they were then centrifuged at maximum speed for $10 \mathrm{~min}$, and the supernatant was collected. Next, $300 \mu \mathrm{l}$ of chloroform and $300 \mu \mathrm{l}$ of Milli-Q water were added, vigorously mixed, and centrifuged for $5 \mathrm{~min}$ at $6800 \mathrm{~g}$. After phase separation, $100 \mu \mathrm{l}$ of the top hydrophilic layer was collected and dried in a vacuum. Samples were derivatized by adding $40 \mu \mathrm{l}$ of $20 \mathrm{mg} / \mathrm{ml}$ metoxyamine hydrochloride (Sigma-Aldrich) dissolved in pyridine following incubation for $2 \mathrm{~h}$ in an orbital shaker at $1000 \mathrm{rpm}$ at $37^{\circ} \mathrm{C}$. Next, N-methyl-N-(trimethylsilyl) tri-fluoroacetamide (MSTFA), including a standard mix (Alkanes) in a volume of $77 \mu \mathrm{l}$, was added to each sample followed by incubation for $30 \mathrm{~min}$ in an orbital shaker at $37^{\circ} \mathrm{C}$. Samples were transferred to glass vials and loaded randomly onto a GC-MS single quadrupole mass spectrometer instrument (Agilent Technologies, Santa Clara, CA, USA). Then, $1 \mu \mathrm{l}$ of the sample was injected into an inert flow path split/splitless inlet with glass wool (Restek, USA) in a 15:1 split ratio on a VF-5 ms capillary column (30 m long) with $0.25 \mathrm{~mm}$ i.d. and $0.25 \mu \mathrm{m}$ film thickness $+10 \mathrm{~m}$ EZ-Guard (Agilent Technologies, Santa Clara, CA, USA). The Programmed Temperature Vaporisation (PTV) for injected samples ranged from 70 to $300{ }^{\circ} \mathrm{C}$ at $14.5^{\circ} \mathrm{C}$ per sec; the transfer line was at $350^{\circ} \mathrm{C}$, and the ion source was adjusted to $250^{\circ} \mathrm{C}$ with gain factor 1 . Helium was used as a carrier gas with a constant flow rate of $1.8 \mathrm{ml}$ per min. For primary metabolite analysis, the temperature program was as follows: $1 \mathrm{~min}$ isothermal heating at $70^{\circ} \mathrm{C}$, followed by a $1{ }^{\circ} \mathrm{C} / \mathrm{min}$ oven temperature ramp to $76^{\circ} \mathrm{C}$, followed by a $6{ }^{\circ} \mathrm{C} / \mathrm{min}$ oven temperature ramp to $340^{\circ} \mathrm{C}$, and a final $5 \mathrm{~min}$ heating at $340^{\circ} \mathrm{C}$. Mass spectra were recorded at 1.6 scans per second with a mass-to-charge ratio of 70 to 550 scanning range [115]. Data acquisition was conducted by Mass Hunter software and the NIST mass spectral library. Additionally, retention index (RI) libraries (Max-Planck Institute for Plant Physiology in Golm, (http://gmd.mpimp-golm.mpg.de/) were used for validation $[113,116]$. Metabolites were normalized to Dsorbitol ${ }^{13} \mathrm{C}_{6}$ as an internal standard and presented as the relative abundance of the ion counts.

\section{Trichome density}

The upper parts of second leaves (same as those used for applying clip cages) were collected, and chlorophyll was bleached by $70 \%$ ethanol at $85^{\circ} \mathrm{C}$ for $8 \mathrm{~min}$, then rinsed with water. The tissue was placed on glass microscope slides facing to the adaxial side (leaf surface up). Trichome density images were photographed with a digital camera (Axiocam 305 color) connected to a Zeiss Axioplan 2 Upright Light Microscope (Zeiss, Oberkochen, Germany). For each leaf, nine photos were taken, including three from each side (left, right), and three from the middle (top, medium, and bottom positions). We counted the number of trichomes on the edges per $\mathrm{mm}$ and the density in $\mathrm{mm}^{2}$ using ImageJ software (https://imagej.nih.gov/ij/).

\section{Water content in the leaves}

The second leaf $(10 \mathrm{~cm}$ of tissue from the leaf tip) of each 11-day-old wheat seedling was collected. The total fresh weight was measured, and then the samples were placed in $2-3 \mathrm{ml}$ of $5 \mathrm{mM} \mathrm{CaCl} 2$ solution for $8 \mathrm{~h}$ followed by drying in a $60{ }^{\circ} \mathrm{C}$ oven for 3-4 days; the dry weight was then measured. The calculation of the leaf relative water content was previously described [117]. The leaves' fresh, turgid, and dry weights are presented in Additional file 1: Table S6.

\section{Detection of hydrogen peroxide}

To examine the basal level of hydrogen peroxide in wheat leaves, a 3,3'-diaminobenzidine (DAB) staining was used for in situ detection [118]. In accordance with the aforementioned protocol, the second leaves of 11day-old wheat seedlings were gently vacuum-infiltrated with DAB solution. As a control treatment, $10 \mathrm{mM}$ of sodium phosphate was applied to replicate leaves. Following vacuuming, samples were incubated in a DAB solution for $4 \mathrm{~h}$, which was then replaced with a bleaching solution (ethanol: acetic acid: glycerol 3:1:1) to remove the chlorophyll and to visualize the precipitate formed by hydrogen peroxide (which renders precipitates in dark brown).

\section{Chlorophyll content}

Fresh leaf tissues $(50 \mathrm{mg}$ ) were incubated in $5 \mathrm{ml}$ of icecold $80 \%$ acetone for $48 \mathrm{~h}$, centrifuged at $5000 \times \mathrm{g}$ for 5 min, and absorbance was recorded at 663 and $645 \mathrm{~nm}$ wavelenghts. The amount of chlorophyll was calculated following the procedure of Arnon (1949) and expressed in $\mathrm{mg} \mathrm{g}^{-1}$ FW [51]. 


\section{Statistical analysis}

For the principal component analysis (PCA) plot, the data were normalized using regularized log transformation, and the graph was plotted using the ggplot2 package in R. The one- and two-way ANOVAs (analysis of variance) used JMP software (SAS; www.jmp.com). In the two-way ANOVA, the inferior numbers for each $F$ value indicated the degree of freedom and the total number of samples used for the test. Microsoft Excel was used for figure representation. In order to test the three genotype groups, a LRT was performed using DESeq2. LRT is a statistical test, similar to ANOVA, which allows the comparison of all levels of a factor at once. The number of clusters $(k)$ was estimated using clusGap [44], and $k$-means clustering was performed with the $\mathrm{k}$-means base function in $\mathrm{R}$. The resulting gene clusters were evaluated for over- and under-representation with agriGO v2 [46].

\section{Supplementary information}

Supplementary information accompanies this paper at https://doi.org/10. 1186/s12870-019-2214-z

Additional file 1: Table S1. Mapping sequence reads to the Chinese Spring reference genome. Table S2. Total RNA-seq values after rlog normalization. Annotations to the D subgenome or an unidentified subgenome $(U)$ were eliminated. Table S3. Distribution of wheat genes into the eight clusters. Table S4. Gene annotation including the International Wheat Genome Sequencing Consortium database (IWGSC) and Phytozome gene ID. Table S5. Biological processes from the Singular Enrichment Analysis with agriGO v2 for significantly differentially expressed genes between each pair of genotypes. The data was divided into the eight $k$-means clusters. Only statistically significant GO terms are shown (FDR < 0.05). Queryitem: the number of genes containing the GO annotation; Querytotal: the total number of genes with $\mathrm{GO}$ annotations; bg item: the number of genes in wheat with this $\mathrm{GO}$ annotation; and bg total: the total number of genes in wheat with GO annotations. Table S6. Metabolites identified in leaves of 11-day-old wheat seedlings analyzed by GCMS. The metabolites were normalized to the internal standard and presented as the relative abundance of the ion counts. Table S7. Weights of wheat leaf tissue used for water content calculation. The fresh, turgid and dry weights are measured in mg. Table S8. A full list of the Bx genes in bread wheat. The data include genes from Subgenome A, B, D, and $U$ (not classified). Table S9. A full list of the trichome formation and regulation genes in bread wheat. The data include genes from Subgenome A, $B, D$, and $U$ (not classified). Table S10. Benzoxazinoid annotation and fragment patterns detected and identified in wheat leaves by UPLC-

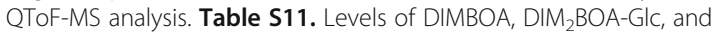
HDMBOA-Glc metabolites detected by HPLC-UV. Calibration curves were calculated by running authentic standards and crude extracts in different concentrations ranging from $0.5-50 \mu \mathrm{g} / \mathrm{ml}$. The peak area of each compound was measured using Chromeleon software, and the final concentration was normalized to mg per gram fresh weight.

Additional file 2: Figure S1. Photos of the wheat genotypes used for this research over 11-18 days after germination. The plants possessed a similar phenology. Figure S2. Heatmap of differentially expressed genes from a likelihood ratio test (LRT) with the DESeq2 $\mathrm{R}$ package. The analytic output was subjected to rlog transformation. The heatmap presents hierarchical clustering of the different genotypes (horizontal axis) against hierarchical clustering of the differentially expressed genes (DEGs; vertical axis). The resulting heatmap clearly divided the overall transcriptional profiles of the two domesticated genotypes (Svevo and Chinese Spring) from the wild emmer (Zavitan). Figure S3. The UV spectra of known benzoxazinoids detected in wheat leaves using high-performance liquid chromatography (HPLC-UV).

\section{Abbreviations}

BXD: benzoxazinoid compounds; DIM $\mathrm{BOA}-\mathrm{Gl}$ : 2,4-dihydroxy-7,8-dimethoxy1,4- benzoxazin-3-one glucoside; DIMBOA: 2,4-dihydroxy-7-methoxy-1,4benzoxazin-3-one; DIMBOA-Glc: 2,4-dihydroxy-7-methoxy-1,4-benzoxazin-3one glucoside; HDMBOA: 2-hydroxy-4,7-dimethoxy-1,4-benzoxazin-3-one glucoside

\section{Acknowledgments}

We thank Dr. Noga Sikron Peres for helping with the UPLC-QToF-MS analysis. We also thank Matthias Erb from the University of Bern, Switzerland for kindly providing the benzoxazinoid crude extract, and Prof. Assaf Distelfeld from Tel Aviv University, Israel for providing the wheat seeds.

\section{Authors' contributions}

$\mathrm{ZB}, \mathrm{RS}, \mathrm{BY}, \mathrm{AS}$ and $\mathrm{VT}$ wrote the manuscript and contributed to the literature search and the structure of the manuscript. ZB, RS, BY designed and conducted the research. All authors revised and approved the final version of the manuscript.

\section{Authors' information}

$\mathrm{VT}$ is the chair of Sonnenfeldt-Goldman Career Development in Desert Research.

\section{Funding}

This research was supported by the Binational Agricultural Research and Development Fund (BARD grant number IS-5092-18R). The funders had no role in the study design, data collection, and analysis, decision to publish, or preparation of the manuscript.

\section{Availability of data and materials}

The datasets used and/or analyzed during the current study are available in this manuscript in the supplementary files or from the corresponding author on reasonable request.

\section{Ethics approval and consent to participate}

Not applicable.

\section{Consent for publication}

Not applicable.

\section{Competing interests}

The authors declare that they have no competing interests.

Received: 20 August 2019 Accepted: 22 December 2019

Published online: 13 January 2020

\section{References}

1. Machado S, Bynum ED, Archer TL, Lascano RJ, Wilson LT, Bordovsky J, et al. Spatial and temporal variability of corn growth and grain yield: implications for site-specific farming. Publ Crop Sci. 2002;42:1564-76.

2. De Geyter E, Lambert E, Geelen D, Smagghe G. Novel advances with plant Saponins as natural insecticides to control Pest insects. Pest Technol. 2007;1:96-105.

3. Rebijith KB, Asokan R, Hande HR, Joshi S, Surveswaran S, Ramamurthy W, et al. Reconstructing the macroevolutionary patterns of aphids (Hemiptera: Aphididae) using nuclear and mitochondrial DNA sequences. Biol J Linn Soc. 2017;121:796-814. https://doi.org/10.1093/biolinnean/blx020.

4. Goggin FL. Plant-aphid interactions: molecular and ecological perspectives. Curr Opin Plant Biol. 2007:10:399-408 Elsevier Current Trends.

5. Bing JW, Novak MG, Obrycki JJ, Guthrie WD. Stylet penetration and feeding sites of Rhopalosiphum maidis (Homoptera: Aphididae) on two growth stages of maize. Ann Entomol Soc Am. 1991;84:549. https://doi.org/10.1093/ aesa/84.5.549

6. Rabbinge $R$, Drees EM, van der Graaf M, Verberne FCM, Wesselo A. Damage effects of cereal aphids in wheat. Neth J Plant Pathol. 1981;87:217-32.

7. Zhou S, Lou Y-R, Tzin V, Jander G. Alteration of plant primary metabolism in response to insect herbivory. Plant Physiol. 2015;169:1488-98.

8. Leybourne DJ, Valentine TA, Robertson JAH, Pérez-Fernández E, Main AM, Karley AJ, et al. Defence gene expression and phloem quality contribute to mesophyll and phloem resistance to aphids in wild barley. J Exp Bot. 2019; 70:4011-26. https://doi.org/10.1093/jxb/erz163. 
9. Markovich O, Kafle D, Elbaz M, Malitsky S, Aharoni A, Schwarzkopf A, et al. Arabidopsis thaliana plants with different levels of aliphatic- and indolylglucosinolates affect host selection and performance of Bemisia tabaci. J Chem Ecol. 2013;39:1361-72. https://doi.org/10.1007/s10886-013-0358-0.

10. Ahuja I, Rohloff J, Bones AM, Magnar A, Defence B. Defence mechanisms of Brassicaceae : implications for plant-insect interactions and potential for integrated pest management. A review. Agron Sustain Dev. 2010;30:311-48.

11. Bennett RN, Wallsgrove RM. Secondary metabolites in plant defence mechanisms. New Phytol. 1994;127:617-33. https://doi.org/10.1111/j.14698137.1994.tb02968.x Blackwell Publishing Ltd.

12. Boughton AJ, Hoover K, Felton GW. Methyl jasmonate application induces increased densities of glandular trichomes on tomato, Lycopersicon esculentum. J Chem Ecol. 2005;31:2211-6. https://doi.org/10.1007/s10886005-6228-7.

13. van Loon LC, Rep M, Pieterse CMJ. Significance of inducible defense-related proteins in infected plants. Annu Rev Phytopathol. 2006;44:135-62. https:// doi.org/10.1146/annurev.phyto.44.070505.143425.

14. Ebisui K, Ishihara A, Hirai N, Iwamura H. Occurrence of 2,4-Dihydroxy-7methoxy-1,4-benzoxazin-3-one (DIMBOA) and a ß-Glucosidase specific for its Glucoside in maize seedlings. Z Naturforsch. 1998;53:793-8.

15. Nomura T, Nasuda S, Kawaura K, Ogihara Y, Kato N, Sato F, et al. Structures of the three homoeologous loci of wheat benzoxazinone biosynthetic genes $\mathrm{TaB} \times 3$ and $\mathrm{TaB} \times 4$ and characterization of their promoter sequences. Theor Appl Genet. 2008;116:373-81.

16. Nomura T, Ishihara A, Yanagita RC, Endo TR, Iwamura H. Three genomes differentially contribute to the biosynthesis of benzoxazinones in hexaploid wheat. Proc Natl Acad Sci U S A. 2005;102:16490-5.

17. Kerchev PI, Fenton B, Foyer CH, Hancock RD. Plant responses to insect herbivory: interactions between photosynthesis, reactive oxygen species and hormonal signalling pathways. Plant Cell Environ. 2012;35:441-53.

18. FAOSTAT. FAO Statistical Database: Food and Agriculture Organization of the United Nations. 2014. Available from: http://faostat3.fao.org/home/E

19. Peleg Z, Fahima T, Korol AB, Abbo S, Saranga Y. Genetic analysis of wheat domestication and evolution under domestication. J Exp Bot. 2011;62:5051-61.

20. Pont C, Leroy T, Seidel M, Tondelli A, Duchemin W, Armisen D, et al. Tracing the ancestry of modern bread wheats. Nat Genet. 2019;51:905-11. https:// doi.org/10.1038/s41588-019-0393-z.

21. Doebley JF, Gaut BS, Smith BD. The molecular genetics of crop domestication. Cell. 2006;127:1309-21. Available from: http://www. sciencedirect.com/science/article/pii/S0092867406015923.

22. Eyre-Walker A, Gaut RL, Hilton H, Feldman DL, Gaut BS. Investigation of the bottleneck leading to the domestication of maize. Proc Natl Acad Sci. 1998;95:4441 LP-4446. Available from: http://www.pnas.org/content/ 95/8/4441.abstract.

23. Reif JC, Zhang P, Dreisigacker S, Warburton ML, van Ginkel M, Hoisington D, et al. Wheat genetic diversity trends during domestication and breeding. Theor Appl Genet. 2005;1 10:859-64. https://doi.org/10.1007/s00122-004-1881-8.

24. Chaudhary B. Plant domestication and resistance to herbivory. Int J Plant Genomics. 2013;2013:14. https://doi.org/10.1155/2013/572784 Hindawi Limited.

25. Moreira X, Abdala-Roberts L, Gols R, Francisco M. Plant domestication decreases both constitutive and induced chemical defences by direct selection against defensive traits. Sci Rep. 2018;8:12678. https://doi.org/10. 1038/s41598-018-31041-0.

26. All JN, Boerma HR, Todd JW. Screening soybean genotypes in the greenhouse for resistance to insects. Crop Sci. 1989;29:1156 Crop Science Society of America.

27. Luedders VD, Dickerson WA. Resistance of selected Soybean Genotypes and Segregating Populations to Cabbage Looper Feeding1. Crop Sci. 1977;17: 395 Crop Science Society of America.

28. Ashfield T, Danzer JR, Held D, Clayton K, Keim P, Saghai MA, et al. Rpg1, a soybean gene effective against races of bacterial blight, maps to a cluster of previously identified disease resistance genes. Theor Appl Genet. 1998;98:1013-21.

29. Garcia A, Calvo ÉS, De Souza Kiihl RA, Harada A, Hiromoto DM, Vieira LGE. Molecular mapping of soybean rust (Phakopsora pachyrhizi) resistance genes: discovery of a novel locus and alleles. Theor Appl Genet. 2008;117:545-53.

30. Chandrasekhar K, Shavit R, Distelfeld A, Christensen S, Tzin V. Exploring the metabolic variation between domesticated and wild tetraploid wheat genotypes in response to corn leaf aphid infestation. Plant
Signal Behav. 2018;13:e1486148. https://doi.org/10.1080/15592324.2018. 1486148 Taylor \& Francis.

31. Gaillard MDP, Glauser G, Robert CAM, Turlings TCJ. Fine-tuning the 'plant domestication-reduced defense' hypothesis: specialist vs generalist herbivores. New Phytol. 2018;217:355-66. https://doi.org/10.1111/nph.14757 John Wiley \& Sons, Ltd (10.1111).

32. Coppola M, Diretto G, Digilio MC, Woo SL, Giuliano G, Molisso D, et al Transcriptome and metabolome reprogramming in tomato plants by trichoderma harzianum strain T22 primes and enhances defense responses against aphids. Front Physiol. 2019;10:745. Available from: https://www. frontiersin.org/article/10.3389/fphys.2019.00745.

33. Åhman I, Kim S-Y, Zhu L-H. Plant genes benefitting aphids-potential for exploitation in resistance breeding. Front Plant Sci. 2019;10:1452. Available from: https://www.ncbi.nlm.nih.gov/pmc/articles/PMC6874142/. Frontiers Media S.A.

34. Radchenko E. Resistance of Triticum species to cereal aphids. Czech J Genet Plant Breed. 2011:47:2009-12. Available from: https://www. agriculturejournals.cz/publicFiles/48956.pdf.

35. Migui SM, Lamb RJ. Patterns of resistance to three cereal aphids among wheats in the genus Triticum (Poaceae). Bull Entomol Res. 2003;93:323-33. Available from: https://www.cambridge.org/core/article/patterns-ofresistance-to-three-cereal-aphids-among-wheats-in-the-genus-triticumpoaceae/A9AEAF6151A7E7ADD15BEF06909A1238. Cambridge University Press. 2007/03/01.

36. Sela H, Ezrati S, Ben-Yehuda P, Manisterski J, Akhunov E, Dvorak J, et al. Linkage disequilibrium and association analysis of stripe rust resistance in wild emmer wheat (Triticum turgidum ssp. dicoccoides) population in Israel. Theor Appl Genet. 2014;127:2453-63. https://doi.org/10.1007/s00122-014-2389-5.

37. Avni R, Nave M, Eilam T, Sela H, Alekperov C, Peleg Z, et al. Ultra-dense genetic map of durum wheat $x$ wild emmer wheat developed using the 90K iSelect SNP genotyping assay. Mol Breed. 2014;34:1549-62. Available from: https://link.springer.com/article/10.1007\%2Fs11032-014-0176-2.

38. Appels R, Eversole K, Stein N, Feuillet C, Keller B, Rogers J, et al. Shifting the limits in wheat research and breeding using a fully annotated reference genome. Science. 2018;361:eaar7191. Available from: http://science. sciencemag.org/content/361/6403/eaar7191.abstract.

39. Law CN, Snape JW, Worland AJ. Aneuploidy in wheat and its uses in genetic analysis. In: Wheat Breed. Dordrecht: Springer Netherlands; 1987. p. 71-108.

40. Gale MD, Miller TE. The introduction of alien genetic variation in wheat. In: Wheat Breed. Dordrecht: Springer Netherlands; 1987. p. 173-210.

41. Endo TR, Gill BS. The deletion stocks of common wheat. J Hered. 1996;87: 295-307 Oxford University Press.

42. Liu M, Rathjen T, Weligama K, Forrest K, Hayden M, Delhaize E. Analysis of aneuploid lines of bread wheat to map chromosomal locations of genes controlling root hair length. Ann Bot. 2017;119:1333-41. Available from: https://www.ncbi.n/m.nih.gov/pubmed/28402495. Oxford University Press. 2017/04/11.

43. Liu D, Zhang L, Hao M, Ning S, Yuan Z, Dai S, et al. Wheat breeding in the hometown of Chinese spring. Crop J. 2018;6:82-90.

44. Maechler M, Rousseeuw P, Struyf A, Hubert M, Hornik K. Cluster: cluster analysis basics and extensions. In: R Packag. version 2.0.8; 2019. Available from: https://cran.r-project.org/web/packages/cluster/citation.html.

45. Joung J-G, Corbett AM, Fellman SM, Tieman DM, Klee HJ, Giovannoni JJ, et al. Plant MetGenMAP: an integrative analysis system for plant systems biology. Plant Physiol. 2009;151:1758 LP-1768. Available from: http://www. plantphysiol.org/content/151/4/1758.abstract.

46. Yan H, You Q, Tian T, Yi X, Liu Y, Du Z, et al. agriGO v2.0: a GO analysis toolkit for the agricultural community, 2017 update. Nucleic Acids Res. 2017; 45:W122-9. https://doi.org/10.1093/nar/gkx382.

47. Chattopadhyay MK, Tabor CW, Tabor H. Polyamine deficiency leads to accumulation of reactive oxygen species in a spe $2 \Delta$ mutant of Saccharomyces cerevisiae. Yeast. 2006;23:751-61. https://doi.org/10.1002/ yea.1393 John Wiley \& Sons, Ltd.

48. Niu L, Liao W. Hydrogen peroxide signaling in plant development and abiotic responses: crosstalk with nitric oxide and calcium. Front Plant Sci. 2016;7:230. Available from: https://www.ncbi.nlm.nih.gov/pubmed/269736 73. Frontiers Media S.A.

49. Sharma P, Jha AB, Dubey RS, Pessarakli M. Reactive oxygen species, oxidative damage, and antioxidative defense mechanism in plants under stressful conditions. J Bot. 2012;2012:26. 
50. Pospísil P. Production of reactive oxygen species by photosystem II as a response to light and temperature stress. Front Plant Sci. 2016;7:1950. Available from: https://www.frontiersin.org/article/10.3389/fpls.2016.01950.

51. Arnon DI. Copper enzymes is isolated chloroplasts polyphenoloxidase in Beta vulgaris. Plant Physiol. 1949;24:1-15. Available from: https://www.ncbi. nlm.nih.gov/pubmed/16654194.

52. Eckstein A, Zięba P, Gabryś H. Sugar and light effects on the condition of the photosynthetic apparatus of Arabidopsis thaliana cultured in vitro. J Plant Growth Regul. 2012;31:90-101. https://doi.org/10.1007/s00344-011-9222-z.

53. Pelleschi S, Rocher J-P, Prioul J-L. Effect of water restriction on carbohydrate metabolism and photosynthesis in mature maize leaves. Plant Cell Environ. 1997;20:493-503. https://doi.org/10.1046/j.1365-3040.1997.d01-89.x John Wiley \& Sons, Ltd (10.1111).

54. Teulat B, Monneveux P, Wery J, Borries C, Souyris I, Charrier A, et al. Relationships between relative water content and growth parameters under water stress in barley: a QTL study. New Phytol. 1997;137:99-107.

55. Munné-Bosch S, Peñuelas J. Drought-induced oxidative stress in strawberry tree (Arbutus unedo L.) growing in Mediterranean field conditions. Plant Sci. 2004;166:1105-10 Elsevier.

56. Chan $\mathrm{L}$, Fowler $\mathrm{J}$. Validation of relative water content for studying plant water relations in crambe. Ind Crop Prod. 1992:1:21-9. Elsevier.

57. Wilcox DA, Ashley RA. OpenCommons@UConn Storrs agricultural Experiment Station College of Agriculture, health and natural resources leaf diffusive resistance and relative water content as indications of varietal sensitivity to drought in potatoes. Storrs Agric Exp Stn. 1980;62:1-12.

58. Lyons R, Manners JM, Kazan K. Jasmonate biosynthesis and signaling in monocots: A comparative overview. Plant Cell Rep. 2013:815-27.

59. Zulak KG, Bohlmann J. Terpenoid biosynthesis and specialized vascular cells of conifer defense. J Integr Plant Biol. 2010;52:86-97. https://doi.org/10. 1111/j.1744-7909.2010.00910.x John Wiley \& Sons, Ltd (10.1111).

60. Falcone Ferreyra ML, Rius SP, Casati P. Flavonoids: biosynthesis, biological functions, and biotechnological applications. Front Plant Sci. 2012;3:222. Available from: https://www.ncbi.nlm.nih.gov/pubmed/2306 0891. Frontiers Media S.A.

61. Gordon-Weeks R, Smart L, Ahmad S, Zhang Y, Elek H, Jing H, et al. The role of the benzoxazinone pathway in aphid resistance in wheat. HGCA Proj Rep. 2010. Home Grown Cereals Authority (HGCA) Stoneleigh. p. 1-66.

62. Li B, Förster C, Robert CAM, Züst T, Hu L, Machado RAR, et al. A metabolic switch between aphid and caterpillar resistaConvergent evolution of nce in cereals. Sci Adv. 2018;4:1-15 American Association for the Advancement of Science.

63. Glawischnig E, Eisenreich W, Bacher A, Frey M, Gierl A. Biosynthetic origin of oxygen atoms in DIMBOA from maize: NMR studies with 1802. Phytochemistry. 1997;45:715.

64. Jonczyk R, Schmidt H, Osterrieder A, Fiesselmann A, Schullehner K, Haslbeck $M$, et al. Elucidation of the final reactions of DIMBOA-glucoside biosynthesis in maize: characterization of Bx6 and Bx7. Plant Physiol. 2008;146:1053.

65. Meihls LN, Handrick V, Glauser G, Barbier H, Kaur H, Haribal MM, et al. Natural variation in maize aphid resistance is associated with 2,4-dihydroxy-7-methoxy1,4-benzoxazin-3-one glucoside methyltransferase activity. Plant Cell. 2013;25: 1-16. Available from: http://www.ncbi.n/m.nih.gov/pubmed/23898034.

66. Goffreda JC, Steffens JC, Mutschler MA. Association of epicuticular sugars with aphid resistance in hybrids with wild tomato. J Am Soc Hortic Sci. 1990;115:161-5 Gentile and Stoner.

67. Gibson RW, Pickett JA. Wild potato repels aphids by release of aphid alarm pheromone. Nature. 1983;302:608-9 Nature Publishing Group.

68. Li J, Yuan Y, Lu Z, Yang L, Gao R, Lu J, et al. Glabrous Rice 1, encoding a homeodomain protein, regulates trichome development in rice. Rice. 2012; 5:32. https://doi.org/10.1186/1939-8433-5-32 Nature Publishing Group.

69. Zeng $Y$, Zhu Y, Lian L, Xie H, Zhang J, Xie H. Genetic analysis and fine mapping of the pubescence gene GL6 in rice (Oryza sativa L.). Chin Sci Bull. 2013;58:2992-9. https://doi.org/10.1007/s11434-013-5737-y.

70. Vernoud V, Laigle G, Rozier F, Meeley RB, Perez P, Rogowsky PM. The HD-ZIP IV transcription factor OCL4 is necessary for trichome patterning and anther development in maize. Plant J. 2009;59:883-94. https://doi.org/10.1111/j. 1365-313X.2009.03916.x John Wiley \& Sons, Ltd (10.1111).

71. Ahmad S, Veyrat N, Gordon-Weeks R, Zhang Y, Martin J, Smart L, et al. Benzoxazinoid metabolites regulate innate immunity against aphids and fungi in maize. Plant Physiol. 2011;157:317-27.

72. Frey M, Schullehner K, Dick R, Fiesselmann A, Gierl A. Benzoxazinoid biosynthesis, a model for evolution of secondary metabolic pathways in plants. Phytochemistry. 2009;70:1645-51. https://doi.org/10.1016/j. phytochem.2009.05.012 Elsevier Ltd.

73. Zhou S, Kremling KA, Bandillo N, Richter A, Zhang YK, Ahern KR, et al. Metabolome-scale genome-wide association studies reveal chemical diversity and genetic control of maize specialized metabolites. Plant Cell. 2019;31:937 LP-955. Available from: http://www.plantcell.org/content/31/5/ 937.abstract. Elsevier Ltd.

74. Handrick V, Robert CAM, Ahern KR, Zhou S, Machado RAR, Maag D, et al. Biosynthesis of 8-O-methylated benzoxazinoid defense compounds in maize. Plant Cell. 2016;28:1682-1700. Available from: http://www.plantcell. org/lookup/doi/10.1105/tpc.16.00065.

75. Huang Q, Li L, Zheng M, Chen F, Long H, Deng G, et al. The tryptophan decarboxylase 1 gene from Aegilops variabilis No.1 regulate the resistance against cereal cyst nematode by altering the downstream secondary metabolite contents rather than auxin synthesis. Front Plant Sci. 2018;9:1297. Available from: http://www.ncbi.nlm.nih.gov/pmc/articles/PMC6132075/. Frontiers Media S.A.

76. Montenegro JD, Golicz AA, Bayer PE, Hurgobin B, Lee H, Chan C-KK, et al. The pangenome of hexaploid bread wheat. Plant J. 2017;90:1007-13. https://doi.org/10.1111/tpj.13515 John Wiley \& Sons, Ltd (10.1111).

77. Blackman R, Eastop V. Aphids on the world's crops: an identification and information guide. London: Wiley; 2000.

78. Kieckhefer RW, Gellner JL. Influence of plant growth stage on cereal aphid reproduction. Crop Sci. 1988;28:688-90

79. Aradottir Gl, Martin JL, Clark SJ, Pickett JA, Smart LE. Searching for wheat resistance to aphids and wheat bulb fly in the historical Watkins and Gediflux wheat collections. Ann Appl Biol. 2017;170:179-88. https://doi.org/ 10.1111/aab.12326 John Wiley \& Sons, Ltd (10.1111).

80. Niemeyer HM. Hydroxamic acids (4-hydroxy-1,4-benzoxazin-3-ones), defence chemicals in the gramineae. Phytochemistry. 1988;27:3349-58. Available from: http://linkinghub.elsevier.com/retrieve/pii/0031942288807313.

81. Powell JJ, Fitzgerald TL, Stiller J, Berkman PJ, Gardiner DM, Manners JM, et al. The defence-associated transcriptome of hexaploid wheat displays homoeolog expression and induction bias. Plant Biotechnol J. 2017;15:53343. Available from: http://www.ncbi.nlm.nih.gov/pmc/articles/PMC5362679/. Hoboken: John Wiley and Sons Inc.

82. Kashkush K, Feldman M, Levy AA. Gene loss, silencing and activation in a newly synthesized wheat allotetraploid. Genetics. 2002;160:1651-9.

83. Argandora VH, Niemeyer HM, Corcuera LJ. Effect of content and distribution of hydroxamic acids in wheat on infestation by the aphid Schizaphis gramlnum. Phytochemistry. 1981;20:673-6.

84. Cambier V, Hance T, de Hoffmann E. Effects of 1,4-benzoxazin-3-one derivatives from maize on survival and fecundity of Metopolophium dirhodum (Walker) on artificial diet. J Chem Ecol. 2001;27:359.

85. Klun JA, Tipton CL, Brindley TA. 2,4-Dihydroxy-7-methoxy-1,4-benzoxazin-3one (DIMBOA), an active agent in the resistance of maize to the European corn borer. J Econ Entomol. 1967:60:1529.

86. Glauser G, Marti G, Villard N, Doyen GA, Wolfender JL, Turlings TCJ, et al. Induction and detoxification of maize 1,4-benzoxazin-3-ones by insect herbivores. Plant J. 2011;68:901-11.

87. Dafoe NJ, Huffaker A, Vaughan MM, Duehl AJ, Teal PE, Schmelz EA. Rapidly induced chemical defenses in maize stems and their effects on short-term growth of Ostrinia nubilalis. J Chem Ecol. 2011;37:984-91.

88. Oikawa A, Ishihara A, Tanaka C, Mori N, Tsuda M, Iwamura H. Accumulation of $\mathrm{HDMBOA}-\mathrm{Gl}$ is induced by biotic stresses prior to the release of MBOA in maize leaves. Phytochemistry. 2004;65:2995-3001.

89. Niemeyer HM. Hydroxamic acids derived from 2-Hydroxy-2H-1,4Benzoxazin-3(4H)-one: key defense chemicals of cereals. J Agric Food Chem. 2009;57:1677-96.

90. Neal AL, Ahmad S, Gordon-Weeks R, Ton J. Benzoxazinoids in root exudates of maize attract Pseudomonas putida to the rhizosphere. PLoS One. 2012;7:e35498. https://doi.org/10.1371/journal.pone.0035498 Public Library of Science.

91. Kudjordjie EN, Sapkota R, Steffensen SK, Fomsgaard IS, Nicolaisen M. Maize synthesized benzoxazinoids affect the host associated microbiome. Microbiome. 2019;7:59. https://doi.org/10.1186/s40168-019-0677-7.

92. Hu L, Mateo P, Ye M, Zhang X, Berset JD, Handrick V, et al. Plant iron acquisition strategy exploited by an insect herbivore. Science. 2018;697:694-7.

93. Betsiashvili $M$, Ahern KR, Jander G. Additive effects of two quantitative trait loci that confer Rhopalosiphum maidis (corn leaf aphid) resistance in maize inbred line Mo17. J Exp Bot. 2015;66:571-8. 
94. Niculaes C, Abramov A, Hannemann L, Frey M. Plant protection by benzoxazinoids - recent insights into biosynthesis and function. Agronomy. 2018;8:143.

95. Hu L, Mateo P, Ye M, Zhang X, Berset JD, Handrick V, et al. Plant iron acquisition strategy exploited by an insect herbivore. Science. 2018;361:694-7.

96. Hänsch $\mathrm{R}$, Mendel RR. Physiological functions of mineral micronutrients (Cu, Zn, Mn, Fe, Ni, Mo, B, Cl). Curr Opin Plant Biol. 2009;12:259-66. Available from: http://www.sciencedirect.com/science/article/pii/S1369526609000429.

97. Wang M, Kawakami Y, Bhullar NK. Molecular analysis of iron deficiency response in hexaploid wheat. Front Sustain Food Syst. 2019;3:67. Available from: https://www.frontiersin.org/article/10.3389/fsufs.2019.00067.

98. Cambier V, Hance T, de Hoffmann E. Variation of DIMBOA and related compounds content in relation to the age and plant organ in maize. Phytochemistry. 2000:53:223-9.

99. Müller C. Plant-insect interactions on cuticular surfaces. Annu Plant Rev Biol Plant Cuticle. 2006;23:398-422. https://doi.org/10.1002/9780470988718.ch13.

100. Meihls LN, Kaur H, Jander G. Natural variation in maize defense against insect herbivores; 2012.

101. Riddick EW, Simmons AM. Do plant trichomes cause more harm than good to predatory insects? Pest Manag Sci. 2014;70:1655-65. https://doi.org/10. 1002/ps.3772 John Wiley \& Sons, Ltd.

102. Avni R, Nave M, Barad O, Baruch K, Twardziok SO, Gundlach H, et al. Wild emmer genome architecture and diversity elucidate wheat evolution and domestication. Science. 2017;357:93 LP-97. Available from: http://science. sciencemag.org/content/357/6346/93.abstract.

103. Nave M, Avni R, Ben-Zvi B, Hale I, Distelfeld A. QTLs for uniform grain dimensions and germination selected during wheat domestication are COlocated on chromosome 4B. Theor Appl Genet. 2016;129:1303-15. https:// doi.org/10.1007/s00122-016-2704-4.

104. Maccaferri M, Harris NS, Twardziok SO, Pasam RK, Gundlach H, Spannagl M, et al. Durum wheat genome highlights past domestication signatures and future improvement targets. Nat Genet. 2019;51:885-95. https://doi.org/10. 1038/s41588-019-0381-3.

105. Ogihara Y, Isono K, Kojima T, Endo A, Hanaoka M, Shiina T, et al. Chinese spring wheat (Triticum aestivum L.) chloroplast genome: complete sequence and contig clones. Plant Mol Biol Report. 2000;18:243-53. https:// doi.org/10.1007/BF02823995.

106. Sears ER, Miller TE. The history of Chinese spring wheat. Cereal Res Commun. 1985;13:261-3. Available from: http://www.jstor.org/stable/23783 009. Akadémiai Kiadó.

107. Love Ml, Huber W, Anders S. Moderated estimation of fold change and dispersion for RNA-seq data with DESeq2. Genome Biol. 2014;15:550. https://doi.org/10.1186/s13059-014-0550-8.

108. Alaux M, Rogers J, Letellier T, Flores R, Alfama F, Pommier C, et al. Linking the international wheat genome sequencing consortium bread wheat reference genome sequence to wheat genetic and phenomic data. Genome Biol. 2018;19:111. https://doi.org/10.1186/s13059-018-1491-4.

109. The International Wheat Genome Sequencing Consortium (IWGSC). A chromosome-based draft sequence of the hexaploid bread wheat (Triticum aestivum) genome. Science. 2014;345:1251788. Available from: http:// science.sciencemag.org/content/345/6194/1251788.abstract.

110. Mijares V, Meihls LN, Jander G, Tzin V. Near-isogenic lines for measuring phenotypic effects of DIMBOA-Glc methyltransferase activity in maize. Plant Signal Behav. 2013;8:e26779.

111. Shavit R, Batyrshina ZS, Dotan N, Tzin V. Cereal aphids differently affect benzoxazinoid levels in durum wheat. PLoS One. 2018;13:e0208103. https:// doi.org/10.1371/journal.pone.0208103 Public Library of Science.

112. Degu A, Hochberg U, Sikron N, Venturini L, Buson G, Ghan R, et al. Metabolite and transcript profiling of berry skin during fruit development elucidates differential regulation between cabernet sauvignon and shiraz cultivars at branching points in the polyphenol pathway. BMC Plant Biol. 2014;14:188. https://doi.org/10.1186/s12870-014-0188-4.

113. Hochberg U, Degu A, Toubiana D, Gendler T, Nikoloski Z, Rachmilevitch $S$, et al. Metabolite profiling and network analysis reveal coordinated changes in grapevine water stress response. BMC Plant Biol. 2013;13:184 BioMed Central.

114. Hanhineva K, Rogachev I, Aura AM, Aharoni A, Poutanen K, Mykkänen H. Qualitative characterization of benzoxazinoid derivatives in whole grain rye and wheat by LC-MS metabolite profiling. J Agric Food Chem. 2011;59:921-7.

115. Rosental L, Perelman A, Nevo N, Toubiana D, Samani T, Batushansky A, et al. Environmental and genetic effects on tomato seed metabolic balance and its association with germination vigor. BMC Genomics. 2016;17:1047. Available from: http://bmcgenomics.biomedcentral.com/articles/10.1186/s12 864-016-3376-9.

116. Lisec J, Schauer N, Kopka J, Willmitzer L, Fernie AR. Gas chromatography mass spectrometry--based metabolite profiling in plants. Nat Protoc. 2006;1: 387-96.

117. Sade N, Galkin E, Moshelion M. Measuring Arabidopsis, tomato and barley leaf relative water content (RWC). Bio-protocol. 2015;5:e1451.

118. Daudi A, O'Brien J. Detection of hydrogen peroxide by DAB staining in Arabidopsis leaves. Bio-Protocol. 2012;2:e263.

\section{Publisher's Note}

Springer Nature remains neutral with regard to jurisdictional claims in published maps and institutional affiliations.
Ready to submit your research? Choose BMC and benefit from:

- fast, convenient online submission

- thorough peer review by experienced researchers in your field

- rapid publication on acceptance

- support for research data, including large and complex data types

- gold Open Access which fosters wider collaboration and increased citations

- maximum visibility for your research: over $100 \mathrm{M}$ website views per year

At BMC, research is always in progress.

Learn more biomedcentral.com/submissions 